\title{
Therapeutic Applications of Curcumin Nanoformulations
}

\author{
Murali M. Yallapu, ${ }^{1,2}$ Prashanth K. Bhusetty Nagesh, ${ }^{1}$ Meena Jaggi, ${ }^{1}$ and Subhash C. Chauhan ${ }^{1,2}$
}

Received 5 June 2015; accepted 29 July 2015; published online 3 September 2015

Abstract. Curcumin (diferuloylmethane) is a bioactive and major phenolic component of turmeric
derived from the rhizomes of curcuma longa linn. For centuries, curcumin has exhibited excellent
therapeutic benefits in various diseases. Owing to its anti-oxidant and anti-inflammatory properties,
curcumin plays a significant beneficial and pleiotropic regulatory role in various pathological conditions
including cancer, cardiovascular disease, Alzheimer's disease, inflammatory disorders, neurological
disorders, and so on. Despite such phenomenal advances in medicinal applications, the clinical
implication of native curcumin is hindered due to low solubility, physico-chemical instability, poor
bioavailability, rapid metabolism, and poor pharmacokinetics. However, these issues can be overcome by
utilizing an efficient delivery system. Active scientific research was initiated in 2005 to improve
curcumin's pharmacokinetics, systemic bioavailability, and biological activity by encapsulating or by
loading curcumin into nanoform(s) (nanoformulations). A significant number of nanoformulations exist
that can be translated toward medicinal use upon successful completion of pre-clinical and human clinical
trials. Considering this perspective, current review provides an overview of an efficient curcumin
nanoformulation for a targeted therapeutic option for various human diseases. In this review article, we
discuss the clinical evidence, current status, and future opportunities of curcumin nanoformulation(s) in
the field of medicine. In addition, this review presents a concise summary of the actions required to
develop curcumin nanoformulations as pharmaceutical or nutraceutical candidates.

KEY WORDS: cancer; curcumin; drug delivery; nanoparticles; nanotechnology.

\section{INTRODUCTION}

Chemotherapy is a major form of treatment modality for various human diseases and disorders in both developing and developed countries. This intervention has been associated with a number of side effects and poor compliance. Therefore, in recent years, a significant effort has been put forward for finding a better treatment modality that uses natural compounds or extracts. Among many naturally occurring polyphenol compounds, curcumin is a highly safe yellow pigment molecule, widely used as a food coloring agent, and can be used to treat various pathological conditions. Curcumin's use for various disease indications is primarily due to its active biological functions, i.e., anti-inflammatory, anti-oxidant, anti-microbial, anti-Alzheimer, anti-tumor, anti-diabetic, and anti-rheumatic activities $(1,2)$. In addition, curcumin has been proven as a hypoglycemic, hepato-, nephron-, cardio-, and neuro-protective molecule (3). More importantly, this molecule also suppresses thrombosis and protects against myocardial infarction. It is, by far, the most prominent polyphenol, widely consumed on a daily

\footnotetext{
${ }^{1}$ Department of Pharmaceutical Sciences and Center for Cancer Research, College of Pharmacy, The University of Tennessee Health Science Center, Memphis, Tennessee 38163, USA.

${ }^{2}$ To whom correspondence should be addressed. (e-mail: myallapu@uthsc.edu; schauha1@uthsc.edu)
}

basis along with food (in India, Eastern Asia, and some African countries), which leads to better compliance. Curcumin usage began in ancient days; however, in 1949, the first scientific evidence of its anti-bacterial activity at very low concentrations was reported in the journal "Nature" and extensive research began only after 1994. During the last two decades, collective scientific data ( $\sim 8000$ peer-reviewed articles/reports/reviews/opinions, patents, and clinical trials) (Fig. 1a) has proven that curcumin is indeed a potential therapeutic molecule. In addition, this molecule is considered "generally recognized as safe (GRAS)" by the US Food Drug Administration (USFDA) (http://www.nutraingredients-usa.com/Suppliers2/ Sabinsa-gets-FDA-no-objection-letter-for-GRAS-status-of-itsCurcumin-C3-Complex, http://www.google.com/ url? $s a=t \& r c t=j \& q=\& e s r c=s \&$ source $=$ web $\& c d=1 \& c a d=r j a \& u a c-$ $\mathrm{t}=8 \& \mathrm{\& ved}=0 \mathrm{CB} 8 \mathrm{QFj} A \mathrm{~A} \& u r l=\mathrm{http} \% 3 \mathrm{~A} \% 2 \mathrm{~F} \% 2 \mathrm{Fwww}$.researchgate.net\%2Fpublictopics.PublicPostFileLoader.html\%3Fid\%3D543f9169d5a3f25e128b45f3\%26key\%3D8e986fed-99cb-4b43-8d9bbe2c826c0e7c\&ei=XAITVd27LsPOsQSlhoCwBQ\&usg=AFQjCNGX7Z-SnJ2nnrcA0rLo3yO88LQ8fg\&bvm=bv.89217033,d.cWc.). Moreover, the curcumin molecule exhibits a multitargeting ability in various pathological conditions, which allows translation into a therapeutic or nutraceutical agent.

Like many other lipophilic therapeutic small drug molecules, curcumin also has limitations (Fig. 1b) for its efficient use in clinical scenarios, in order to treat disease conditions. These include the following: (i) low hydrophilicity 

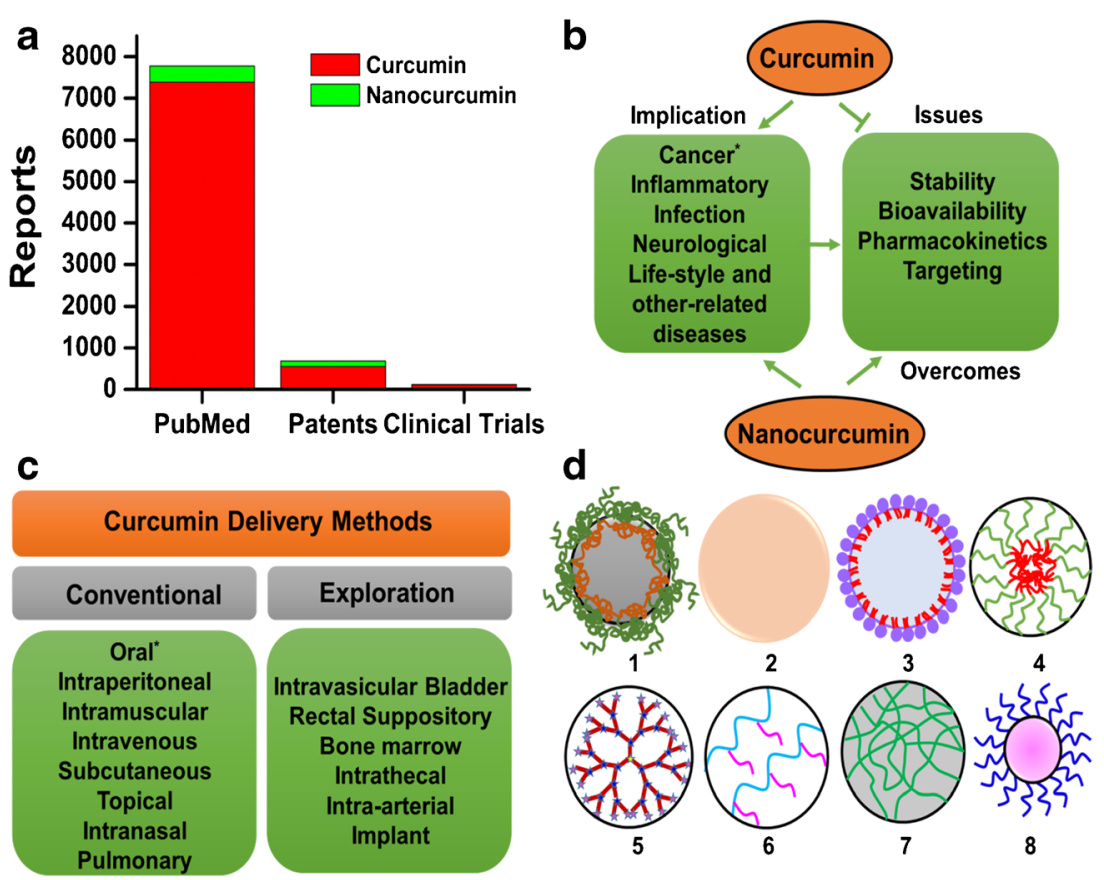

Fig. 1. Schematic transition of "curcumin" into "curcumin nanoformulations". a Graphical represention of literature using PubMed (http://www.ncbi.nlm.nih.gov/pubmed/), patents (Google Patents), and clinical trial (https://clinicaltrials.gov/) websites (search conducted April 2015). b Implication of curcumin and nanocurcumin (curcumin nanoformulations) in various diseases (asterisk indicates widely studied implication). c Feasible delivery methods of curcumin and curcumin nanoformulations (asterisk represents commonly used route to deliver curcumin). d Commonly used types of nanocarriers (1-8: polymer nanoparticles, solid nanoparticles, liposome/lipid nanoparticles, micelles, dendrimers, polymer conjugates, nanogels, and metal/metal oxide nanoparticles, respectively) to deliver curcumin efficiently

and intrinsic dissolution rate(s), (ii) low physico-chemical instability, (iii) rapid metabolization, (iv) low bioactive absorption, (v) poor pharmacokinetics and bioavailability, and (vi) low penetration and targeting efficacy (4-6). All these factors significantly affect the efficient use of curcumin as a therapeutic molecule. Thus, different formulations including native, modified, and micro/nanoforms of curcumin formulations, produced as emulsion, cream, solution, pill, gel, band aid, and so on (7-9), have been designed for conventional or explorative administration (Fig. 1c) to achieve optimum outcomes in various pathological conditions. Both invasive and noninvasive routes of administration have been established for effective local, circulatory, affinity, or active targeting applications (9). Personalized and individual methods of administration may need to be adapted to deliver therapeutic dose of curcumin to the disease site. While there are some critical challenges that need to be addressed, curcumin exhibits numerous strengths, such as its traditional use for centuries; superior biological activity; and extensive pre-clinical, animal, clinical, and human trials that promote rapid development of curcumin or curcumin formulations into medicine(s). These positive indications have encouraged nanotechnologists to design or formulate useful nanocurcumin formulations (Fig. 1d) for improved solubility, stability, cellular uptake/internalization efficacy, specificity, tolerability, and therapeutic index $(7,10)$. Primarily, these newer formulations or compositions may enhance sustained release of curcumin at the cellular targets to improve therapeutic benefit (5).
During the last decade, numerous nanoformulationbased approaches have been undertaken to enhance curcumin use in in vitro, in vivo, and pre-clinical settings that involve the use of adjuvants, stabilizers, conjugates/polymer conjugates, lipid/liposomes, hydro/micro/nanogels, and nanoparticles (NPs) $(7,11,12)$. The specific roles and advantages of each delivery system are presented in Table I. Many of these efforts initially dealt with improved bioavailability, but newer formulations pay attention to efficient targeting of curcumin at the diseased area with the aid of antibody, aptamer, and peptide mediation (10). Efficient curcumin delivery using nanotechnology not only helps to overcome solubility, rapid drug metabolism, degradation, and drug stability issues but also should diffuse or target indent tissues while minimizing unintended toxicity to surrounding normal cells/tissues.

\section{CURCUMIN NANOFORMULATIONS}

Table II documents a number of important recent review articles that have dealt with curcumin nanoformulations. All these documents detail the (i) design of curcumin nanoformulations, (ii) types of different nanocarriers used for curcumin delivery, (iii) improved bioavailability and pharmacokinetics, (iv) human serum protein interactions, and (v) implications for anti-cancer activity. However, there is no review document that specifically describes the use of curcumin nanoformulation(s) in various human disease applications. Therefore, the main emphasis of this review article is to outline the latest developments in nanoparticle- 
Table I. Commonly Used Systems to Deliver Curcumin and Their Specific Advantages over Conventional Systems and Other Nanocarriers

\begin{tabular}{|c|c|c|}
\hline $\begin{array}{l}\text { Type of } \\
\text { nanoformulations }\end{array}$ & Significance and comments & $\begin{array}{l}\text { Number of } \\
\text { publications }\end{array}$ \\
\hline Nanoparticles & $\begin{array}{l}\text { Nanoparticles, in particular, biodegradable nanoparticles, have been used for encapsulation of } \\
\text { curcumin due to its biocompatibility and biodegradability. In fact, some systems have reached } \\
\text { clinical practice. }\end{array}$ & 425 \\
\hline Liposomes & $\begin{array}{l}\text { Liposomes are generated from phospholipid bilayers. This is the second most widely used vehicle } \\
\text { to solubilize/encapsulate curcumin. Various types of liposomes have been tested for delivery of } \\
\text { a number of clinically used drugs and are clinically used in clinics. }\end{array}$ & 139 \\
\hline Cyclodextrins & $\begin{array}{l}\text { Cyclodextrins are cyclic oligosaccharides that can solubilize curcumin in a lipophilic cavity, and the } \\
\text { hydrophilic outer surface helps in greater dispersion of the formulation. }\end{array}$ & 88 \\
\hline Polymers & $\begin{array}{l}\text { Polymers have been exploited to improve solubility and bioavailability of curcumin. Polymeric } \\
\text { carriers have been widely studied for efficient delivery of curcumin. }\end{array}$ & 563 \\
\hline Conjugates & $\begin{array}{l}\text { Conjugation of curcumin to small molecules and hydrophilic polymers is a known practice to } \\
\text { increase aqueous solubility. }\end{array}$ & 69 \\
\hline Micelles & $\begin{array}{l}\text { Micelles or polymeric micelles are composed of amphiphilic block copolymers that spontaneously } \\
\text { form } 20-100 \mathrm{~nm} \text { micelles in aqueous solution at the above critical micellar concentration. The } \\
\text { hydrophobic core of micelles can effectively house curcumin for solubilization and targeted } \\
\text { delivery. }\end{array}$ & 138 \\
\hline Dendrimers & $\begin{array}{l}\text { Dendrimers are composed of highly branched and star-shaped networks of macromolecules. } \\
\text { Typically, dendrimers are formed symmetrically around the core at nanometer-scale dimensions } \\
\text { and are three-dimensionally spherical in morphology. These carriers are highly suitable for } \\
\text { conjugation and loading of curcumin. }\end{array}$ & 13 \\
\hline Lipid nanoparticles & $\begin{array}{l}\text { Lipid nanoparticles are typically spherical in shape with a lipid core matrix that can solubilize } \\
\text { curcumin. The lipid core is usually stabilized by surfactant molecules. }\end{array}$ & 90 \\
\hline Nanogels & $\begin{array}{l}\text { Nanogels are hydrogel nanoparticles of swollen physical/chemically cross-linked networks } \\
\text { composed of hydrophilic or amphiphilic polymer chains. These carriers can be designed to } \\
\text { transport various drug molecules including curcumin. These carriers mimic human tissues due to } \\
\text { higher hydrophilicity in the system due to swollen nature. }\end{array}$ & 12 \\
\hline Gold nanoparticles & $\begin{array}{l}\text { Gold nanoparticles are emerging as a novel platform as photothermal agents, contrast agents, and } \\
\text { radiosensitizers. In addition, current literature supports their use in the delivery of curcumin. }\end{array}$ & 11 \\
\hline Magnetic nanoparticles & $\begin{array}{l}\text { Magnetic nanoparticles are a class of nanoparticles that can be used for multifunctional purposes } \\
\text { including delivery of drugs (curcumin), magnetic resonance imaging, and hyperthermia. }\end{array}$ & 35 \\
\hline Solid dispersions & Solid dispersions are dispersions of curcumin in a suitable inert matrix. & 16 \\
\hline
\end{tabular}

mediated delivery of curcumin $(7,10,14)$ for improved therapeutic outcome.

Nanoparticles (whose size is typically 10-200 $\mathrm{nm}$ in diameter), in general, can improve the circulation time of the loaded therapeutic molecule and improve its residence at the pathological site by enhance permeation and retention (EPR) effect, which is a very important factor in drug delivery technology $(18,19)$, especially in cancer therapeutics. Pre-clinical to clinical implementation of various therapeutic nanoparticle formulations have been under investigation (20). Abraxane (paclitaxel albumin nanoformulation), Doxil (doxorubicin liposome), Genexol-PM (paclitaxel micelle), CALAA-01 (small interfering RNA (siRNA)-targeted nanoformulation), MCC-465 (doxorubicin immunoliposome), and BIND-014 (prostate-specific membrane antigen, PSMA)targeted docetaxel nanoformulation) (21) are well-known and approved USFDA formulations for clinical use or are under clinical trials. Therefore, in this review article, we delineate therapeutic applications of curcumin nanoformulations for various disease treatments by exploiting chemical design, composition, modification, and attachment/ link with targeted motif (19). The use of combinational loading of drugs with curcumin is discussed with emphasis on synergistic action $(22,23)$. Additionally, translational potential and required steps for clinical evaluation of curcumin nanoformulations are summarized.
Significant progress in the development of delivery systems for curcumin (liposome, polymeric nanoparticles, solid lipid nanoparticles, dendrimer, polymer conjugates, micelles, solid lipids, and nanogels) suggests its role in physico-chemical properties and biological activity of nanoformulations. A proposed view of these aspects has been summarized in our recent review articles (7,10). A large body of evidence suggests that curcumin exhibits poor physico-chemical stability and limited solubility in aqueous medium. It undergoes acidic/alkaline degradation, susceptable oxidation, and photodegradation. Thus, most of the earlier studies of curcumin nanoformulations were aimed at improving the stability characteristic of curcumin $(5,17)$. As a first attempt, a curcuminoid-loaded solid-lipid-based nanoformulation exhibited $\approx 440 \mathrm{~nm}$ with $70 \%$ loading in a creambased product stable for 6 months (24). Another investigation showed that poly( $N$-butyl cyanoacrylate) (PBCA) nanoparticles preserve up to $79-89 \%$ of the curcuminoids even in the presence of sunlight for about 6 months at storage conditions, demonstrating 3-5\% reduction due to photodegradation (25). Furthermore, there was no significant change in particle size and zeta potential of curcumin nanoparticles due to storage and degradation. The crystal solid dispersion formulation of curcumin remained $83 \%$ curcumin in its active form upon exposure to UVA/B $\left(750 \mathrm{~W} / \mathrm{m}^{2}\right)$ for $1 \mathrm{~h}$, indicating photochemical stability (26). In addition, this formulation 
Table II. Summary of Review Articles on Curcumin Nanoformulations

\begin{tabular}{l}
\hline Details of review article \\
\hline Bioavailability of curcumin: problems and promises. Anand P, \\
Kunnumakkara AB, Newman RA, Aggarwal BB. Mol Pharm. \\
(2007) 4(6):807-18. (5) \\
Advanced drug delivery systems of curcumin for cancer \\
chemoprevention. Bansal SS, Goel M, Aqil F, Vadhanam MV, \\
Gupta RC. Cancer Prev Res. (2011) 4(8):1158-71. (13) \\
Curcumin nanoformulations: a future nanomedicine for cancer. \\
Yallapu MM, Jaggi M, Chauhan SC. Drug Discov Today. (2012) \\
17(1-2):71-80. (7)
\end{tabular}

Advances in nanotechnology-based delivery systems for curcumin. Sun M, Su X, Ding B, He X, Liu X, Yu A, Lou H, Zhai G. Nanomedicine. (2012) 7(7):1085-100. (14)

Curcumin nanomedicine: a road to cancer therapeutics. Yallapu MM, Jaggi M, Chauhan SC. Curr Pharm Des. (2013) 19(11):1994-2010. (10)

Plasma proteins interaction with curcumin nanoparticles: implications in cancer therapeutics. Yallapu MM, Ebeling MC, Jaggi M, Chauhan SC. Cur Drug Metab. (2013) 14(4):504-15.(15)

Nanocurcumin: a promising therapeutic advancement over native curcumin. Flora G, Gupta D, Tiwari A. Crit Rev Ther Drug Carrier Syst. 2013;30(4):331-68. (16)

Curcumin nanoformulations: a review of pharmaceutical properties and preclinical studies and clinical data related to cancer treatment. Naksuriya O, Okonogi S, Schiffelers RM, Hennink WE. Biomaterials. (2014) 35(10):3365-83. (12)

Nanotechnology-applied curcumin for different diseases therapy. Ghalandarlaki N, Alizadeh AM, Ashkani-Esfahani S, BioMed Res Inter. (2014) Article ID 394264, 23 pages (11)

Recent advances in curcumin nanoformulation for cancer therapy. Lee W-H, Loo C-Y, Young PM, Traini D, Mason RS, Rohanizadeh R. Expert Opin. Drug Deliv. (2014) 11(8):1183-1201 (17)

Dose escalation and pharmacokinetic study of nanoparticle curcumin. Kanai M, Imaizumi A, Otsuka Y, Sasaki H, Hashiguchi M, Tsujiko K, et al. Cancer Chemother Pharmacol. (2012) 69(1):65-70 (18)
Description of review article

This review article is the first attempt to discuss enhanced bioavailability of curcumin for therapeutic application with human disease.

This article describes a broad overview of various delivery systems and discusses future strategies to enable the implementation of such chemopreventive strategies.

This is the first comprehensive review focused on the design and development of various nanoformulations (nanoparticles, selfassemblies, nanogels, liposomes and complex fabrication) for sustained and efficient curcumin delivery. A few novel multifunc tional and composite nanosystem strategies are also discussed due to their simultaneous therapy and imaging characteristics.

This review discusses nanotechnology-based curcumin delivery (liposomes, polymeric nanoparticles, solid lipid nanoparticles, micelles, nanogels, nanosuspensions, nanoemulsions, complexes, and dendrimer/dimer) approaches to enhance oral bioavailability, biological activity, and tissue-targeting ability.

This study reviews advanced drug delivery of curcumin to leverage therapeutic benefits by improving bioavailability and pharmacokinetics for tumor-specific curcumin.

This review examines possible interactions between the surface of curcumin nanoparticles and plasma proteins, the role of nanoparticle-protein complex architecture parameters, and the rational design of clinically useful curcumin nanoformulations.

This review discusses various nanometric formulations of curcumin for its controlled and targeted delivery. It also demonstrates the biological applications, patented technologies, and current status of the ongoing clinical trials related to curcumin nanoformulations.

This review summarizes the design and development of curcumin nanoformulations utilizing liposomes, polymeric nanoparticles and micelles, conjugates, peptide carriers, cyclodextrins, solid dispersions, lipid nanoparticles, and emulsions. Up-to-date efficacy of curcumin nanoformulations using cancer cell lines, in vivo models, and human clinical trials is also provided.

New additions of nanotechnology approaches for curcumin delivery using liposomes, micelles, niosomes, cyclodextrins, dendrimers, nanogels, chitosans, gold nanoparticles, silver, and solid lipid nanoparticles are reported.

This review reports (1) key properties of nanoparticles: size, surface modification, and targeting; (2) development of liposomal, mi celles, nanogels, cyclodextrin-curcumin complexes, and other formulations; and (3) in vitro and in vivo efficacy of curcumin nanoformulations.

Theracurmin can safely increase plasma curcumin levels in a dosedependent manner at least up to $210 \mathrm{mg}$ without saturating the absorption system. exhibited 16-fold increase in the oral bioavailability of curcumin in the male Sprague-Dawley rats. The inclusion complexes or self-assemblies of curcumin and cyclodextrin or poly(cyclodextrin) exhibiting $\approx 88 \%$ remained in active form $(27,28)$. Similarly, a number of nanoformulations have been proven to enhance the physico-chemical stability of curcumin upon incorporating in nanosized particles.

The critical physico-chemical and biological properties depend on the type of preparative method, composition, particle size, particle shape, surface charge, stability, curcumin loading and its release, surface modification and functionalization, bioavailability, and pharmacokinetics of developed curcumin nanoformulations (Fig. 2). Apart from various reports, our (10) recent review article composed of 30 curcumin nanoformulations dealing with "(1) various principles to encapsulate curcumin molecule in various nanoformulations and to prepare curcumin nanoformulations, their composition, and particle evaluation; (2) curcumin loading, release, and uptake behavior of various curcumin nanoformulations; (3) pharmacokinetics properties and bioavailability of curcumin nanoformulations"; and (4) the potential of curcumin nanoformulation. Therefore, readers are encouraged to read the review article (10) for all typical pharmaceutical (preparation, characterization), biopharmaceutical (bioavailability and PK-PD), and potential aspects of various curcumin nanoformulations and below "Preparative 


\section{Curcumin nanoformulation}

\begin{tabular}{|c|c|}
\hline Composition & Curcumin loading \\
Preparative method & Curcumin release \\
Type of formulation & Surface modification \\
Particle size $\&$ shape & Targeting ligand \\
Surface charge & Bioavailability \\
Stability & Pharmacokinetics \\
\hline
\end{tabular}

Fig. 2. Critical physico-chemical properties and biological functions to consider in generating a successful curcumin nanoformulation

Method," "Size, Shape, Surface Charge, and Composition of Nanoparticles," "Curcumin Loading and Release," and "Surface Bio-Functionalization" sections.

\section{Preparative Method}

Curcumin nanoparticles are usually prepared by (i) dispersing polymer or co-polymers and surfactants (solvent evaporation, spontaneous emulsification/solvent diffusion, nanoprecipitation, salting out/emulsion-diffusion, supercritical fluid technologies, etc.); (ii) polymerization of monomers; (iii) reduction or oxidation of metal salts; (iv) pulverization of bulk formulations; and (iv) chemical modification. Each method produces nanoparticles with distinctly different physico-chemical properties.

\section{Size, Shape, Surface Charge, and Composition of Nanoparticles}

Nanoparticles with a 10-200 nm hydrodynamic diameter are highly suitable for medicinal applications. However, for local therapeutic applications, even micro-size particles serve a purpose. The spherical-shaped particle is usually produced by conventional preparative methods. Recent studies also involve the generation of various shapes of nanoparticles. The surface and its charge on nanoparticles offer immediate bio-nanointeractions with cells. A slight positive charge (cationic groups) on the surface of nanoparticles is considered ideal because it increases internalization capacity while higher positive charge contributes to the significant toxicity to the cells. On the other hand, negative charge (anionic groups) promotes a particle's stability in circulation. Recent review articles describe particle size, shape, surface charge, and its implications in elimination from the body (cutoff by kidney and vascular, blood-brain barrier cutoff), EPR, and active targeting $(7,10,17)$.

\section{Curcumin Loading and Release}

Curcumin is a less potent molecule than many clinically used chemotherapy drugs; therefore, its higher loading and encapsulation in nanoparticles may be useful because of its immediate availability to the cells when released from the nanoparticles. As found in literature, curcumin can be loaded up to $25 \mathrm{wt} / \mathrm{wt} \%$. Each method of preparation determines its encapsulation efficiency and release phenomenon. Cellular microenvironment plays a major role in degradation of nanoparticles and curcumin release from the nanoformulations. These properties can be used as external stimuli for targeted delivery of curcumin.

\section{Surface Bio-Functionalization}

Functionalizing a specific antibody, ligand, peptide, or aptamer to the surface of nanoparticles that promotes specific interaction with intended cells is highly relevant. Such formulations bind via receptor proteins to the specifically overexpressing proteins on cell membrane. This creates an opportunity for targeted delivery of curcumin to diseased site.

\section{Scale-Up Process}

Developing a successful scale-up and manufacturing a pharmaceutical-grade curcumin nanoformulation are considerable challenge. It may be suitable for a top-down approach where bulk curcumin nanotized using milling method (a traditional process of producing drug nanocrystals). NanoCrystals $^{\circledR}$ technology is already a developed area of technology which can be adopted for developing curcumin nanoformulations as well. However, this technology may not offer a great monodispersity of nanoparticles (often lead to polydispersity). Additionally, particle size of nanotized curcumin nanoparticles is slightly bigger. Considering all these aspects, a bottom-up approach-based nanoparticle generation with curcumin encapsulation is an alternative promising approach. Recently published data demonstrates various steps involved in scaling up of the nanoformulation process that are essential for the development of a poly(lactide-co-glycolide)-based curcumin nanoparticle formulation (29). This process involves optimizing and scalingup using solid-oil/water emulsion technique. This scale-up process was designed for a 5-g batch by changing the feeds of polymer (PLGA), stabilizer (PVA), solvent (ethyl acetate), sonication tip, and sonication time. The ideal parameters that were created produce curcumin nanoparticles with a particle size of $158.5 \pm 9.8 \mathrm{~nm}$ (polydispersity of $0.141 \pm 0.011$ ) and encapsulation efficiency of $90.34 \pm 2.3$ with a curcumin loading of about $10.32 \pm 1.4 \%$. Various companies (NanoLiposomes, USA; Life Enhancement Products, Inc., USA; Bestvite Inc., USA, Konark Herbals \& Health Care, India; Advanced Orthomolecular Research, Inc., Canada; International Nutrition, Inc., USA; Lee Silsby Compounding Pharmacy, USA; Nano Tech Miso, Korea, Sabinsa Corporation, USA; etc.) (7) produce curcumin nanoformulations. Sabinsa Corporation is notably highly involved in both research and development aspects of curcumin C3 complexes. Signpath Corporation (http://signpathpharma.com) is in the process of developing three pharmaceutical-grade intravenous nanoparticle-sized formulations, namely, liposomal, polymeric, and PLGA nanoformulations. Their products have been examined for proof of efficacies against human tumor xenografts. Additionally, in collaboration with the Nanotechnology Characterization Laboratory, their nanoformulations were evaluated for endotoxin analysis, particle size and zeta potential, in vitro cellular cytotoxicity, immunological assays, metabolism, and pharmacokinetic studies before actual implementation (documented as NCL201304A report, http://www.signpathpharma.com/resources/NCLCharacterizationNanocurcuminPharma.pdf). 
Additional steps to further develop curcumin nanoformulations for efficient use in clinical settings have been suggested in "Expert Opinion" section.

\section{THERAPEUTIC APPLICATIONS OF CURCUMIN NANOFORMULATIONS}

From the literature, it is evident that poor solubility, bioavailability, and pharmacokinetics are major barriers to the clinical translational use of curcumin. Various strategies (mentioned in Table I) have been developed to overcome these problems. In numerous in vitro and in vivo studies, nanoformulations of curcumin exhibited superior therapeutic benefits over the free curcumin $(7,10)$ in a side-by-side setting ("Cancer," "Cardiovascular Diseases," "Neurodegenerative, Alzheimer's, and Brain Diseases," "Stroke," "Inflammatory Diseases," "Diabetes," "Lung Diseases," "Anti-Microbial and Wound Healing," "Ophthalmic," "Skin Diseases," "Malaria," "Cystic Fibrosis," "Osteoporosis," and "HIV" sections). Recent clinical trials demonstrate that curcumin nanoformulations exhibit improved bioavailability of curcumin (Table III) and thus provide a strong rationale for future clinical use once additional important mechanistic perspectives are understood. In this section, we precisely discuss the use of various curcumin nanoformulations in a number of diseases. Although, there is no report out there demonstrating clinical benefit of curcumin nanoformulation, but since curcumin nanoformulation(s) have shown superior outcomes in both in vitro and in vivo studies, we believe that greater effects can be expected from curcumin nanoformulations over free curcumin.

\section{Cancer}

Following heart diseases, cancer is still the second leading cause of death in human. The most commonly used treatment modalities include surgery, chemotherapy, radiation therapy, targeted therapy, immunotherapy, hyperthermia, photothermic therapy, and other alternative therapies. Traditionally, chemotherapy is highly recommended for both solid and metastatic tumors. However, chemotherapyassociated side effects are quite deleterious to normal/ healthy tissues/organs. Thus, curcumin and its nanoformulations play a significant role in enhancing chemo/radiosensitization and can act as treatment modality to provide a proper dose at the tumor site. This section deals with how curcumin nanoformulations efficiently reduce the growth and metastasis potential of tumor cells or tumor burden. Curcumin nanoformulations significantly internalize in cancer cells through endocytosis or receptor-mediated pathways in the presence of endocytosis inhibitors and release curcumin in active form in order to induce its biological effects $(30,31)$. Dextran-CCM nanoparticles were significantly taken up in HeLa cells while very minimal uptake was found in two normal cell lines. Furthermore, curcumin nanoformulations retain molecular targeting effects, even though curcumin is encapsulated in nanoparticles or nanocarrier. Our previous review article documented a number of curcumin formulations and discussed their in vitro and in vivo effects against cancer cell proliferation and tumor progression (7). More importantly, Maitra's group has engineered a curcumin nanoformulation (NanoCurc ${ }^{\mathrm{TM}}$ ) (32-34). This formulation was developed by a random copolymerization of $N$-isopropylacrylamide with $N$-vinyl-2-pyrrolidone, poly(ethylene glycol)-monoacrylate in the presence of $N, N^{\prime}$-methylenebisacrylamide, ammonium persulfate, ferrous ammonium sulfate, and tetramethylethylenediamine. This formulation produced micellar aggregates of $50 \mathrm{~nm}$ amphiphilic polymers which release $40 \%$ of curcumin at physiological $\mathrm{pH}$. NanoCurc formulation possesses high systemic bioavailability in plasma and tissues over free curcumin (32-34). Widely tested in animal studies for cancer treatment (35-38), this formulation demonstrated tumor growth inhibition attributed to significant reduction in activation of nuclear factor kappa $\mathrm{B}(\mathrm{NF}-\mathrm{kB})$, inhibition in the expression of matrix metalloproteinase-9 (MMP-9) and cyclin D1. The combination of NanoCurc ${ }^{\mathrm{TM}}$ and gemcitabine indicated an additive therapeutic effect (37).

A recent study demonstrated that a number of newer approaches exist to deliver curcumin with augmented activity. For instance, layer-by-layer deposition of polyelectrolytes (polystyrene sulfonate/polyallylamine hydrochloride, polyglutamic acid/poly-l-lysine, dextran sulfate/protamine sulfate, and carboxymethyl cellulose/gelatin loaded with curcumin formulations) blocks the hepatocyte growth factorinduced signaling in the breast cancer cell line, MDA-MB-231 (39). Curcumin encapsulation in Eudragit S100 polymer nanoparticles, which dissolves at colonic $\mathrm{pH}$, influences cellular uptake and exhibits a two-fold superior anti-cancer potential in HT-29 human colorectal cell line (40). Novel formulations allow a multitheranostic approach in which imaging and therapeutic function are included (41-44). Such curcumin nanoformulations are usually built with gold $(45,46)$ and magnetic $(47,48)$ nanoparticles. Additionally, dual layers of magnetic and gold nanoparticle (magnetoplasmonic nanoparticles) not only incorporate high-contrast magnetic resonance imaging properties but also enhance apoptosis in leukemia HL-60 cells (49). Some of these curcumin nanoformulations make an augmented approach possible by combining mild hyperthermia, $\mathrm{pH}$, radiofrequency (RF), and thermosensitivity (50-52). For example, a composite chitosan$g$-poly $(N$-vinyl caprolactam $)$ nanoparticle with embedded gold nanoparticles encapsulated with curcumin exhibits controlled release of curcumin and apoptosis to cancer cells. Additionally, this composite formulation confirms its residence in internal tumors for a week, which can offer potential new avenues of RF-assisted cancer treatment (53). Magnetic nanoparticles of curcumin could increase in temperature under an external magnetic field, which can induce hyperthermia potential in cancer therapy.

Targeted delivery of curcumin using nanoparticles is always more advantageous over conventional formulations. We reported that PSMA-targeted curcumin PLGA NPs specifically target PSMA overexpressing prostate cancer cells both in cell line and xenograft tumors (30). Development of a number of targeted curcumin nanoformulations has been presented in Table IV.

\section{Cardiovascular Diseases}

Proliferation and migration of vascular smooth muscle cells (VSMCs) are observed during vascular development in response to vascular injury and atherogenesis. Vascular injury 
Table III. Clinical Trials Dealing with Curcumin Nanoformulations and the Study Outcome

\begin{tabular}{|c|c|}
\hline Type of nanoformulations & Purpose outcome or outcome measures \\
\hline $\begin{array}{l}\text { Study investigating the ability of plant exosomes to deliver curcumin } \\
\text { to normal and colon cancer tissue (NCT01294072) Phase I } \\
\text { (recruiting); University of Louisville, USA. }\end{array}$ & $\begin{array}{l}\text { To investigate the ability of plant exosomes to deliver curcumin to } \\
\text { normal colon tissue and colon tumors and to compare to oral } \\
\text { tablets of curcumin alone. }\end{array}$ \\
\hline $\begin{array}{l}\text { Improved oral bioavailability of curcumin incorporated into micelles } \\
\text { (NCT01982734) Phase } 0 \text { (recruiting); University of Hohenheim, } \\
\text { Germany. }\end{array}$ & $\begin{array}{l}\text { To test the application of phytochemicals and micellar solubilization, } \\
\text { alone and together, to enhance the absorption of curcumin into the } \\
\text { body. For this, the plasma concentrations of curcumin, } \\
\text { demethoxycurcumin, and bisdemethoxycurcumin are evaluated. } \\
\text { Also, to evaluate serum asparate transaminase, alanine, gamma- } \\
\text { glutamyl transferase, phosphatase, bilirubin, uric acid, creatinine, } \\
\text { total cholesterol, HD/LDL cholesterol, and triglycerols. }\end{array}$ \\
\hline $\begin{array}{l}\text { Oral bioavailability of curcumin from micronized powder and liquid } \\
\text { micelles in healthy young women and men (NCT01925287) Phase } \\
0 \text { (completed); University of Hohenheim, Germany. }\end{array}$ & $\begin{array}{l}\text { This study was aimed to develop novel curcumin formulations with } \\
\text { enhanced oral bioavailability and to study the safety of the } \\
\text { formulations in humans. A single oral dose of } 500 \mathrm{mg} \text { curcumin as } \\
\text { native powder, micronized powder, or liquid micelles resulted in an } \\
\text { area under the plasma concentration-time curve. The micronized } \\
\text { curcumin exhibited 14-, 5-, and 9-fold and micellar curcumin } 277-\text {, } \\
\text { 114-, and } 185 \text {-fold better bioavailability than native curcumin in } \\
\text { women, men, and all subjects, respectively. }\end{array}$ \\
\hline $\begin{array}{l}\text { Evaluation of liposomal curcumin in healthy volunteers } \\
\text { (NCT01403545) Phase I (completed); Medical University of } \\
\text { Vienna, Austria. }\end{array}$ & $\begin{array}{l}\text { Safety and tolerability of increasing doses of intravenous liposomal } \\
\text { curcumin in healthy subjects by means of adverse events, vital signs, } \\
\text { and safety laboratory assessments was evaluated. Liposomal } \\
\text { curcumin was tolerated well, but a transient red blood cell } \\
\text { echinocyte formation with concomitant increase in mean cellular } \\
\text { volume was observed at dosages } \geq 120 \mathrm{mg} / \mathrm{m}^{2} \text {. }\end{array}$ \\
\hline $\begin{array}{l}\text { Micro-Particle Curcumin for the Treatment of Chronic Kidney } \\
\text { Disease (NCT02369549) Phase III (recruiting), Lawson Health } \\
\text { Research Institute, The Kidney Foundation of Canada, and } \\
\text { Canadian Institutes of Health Research, Canada. }\end{array}$ & $\begin{array}{l}\text { This is an investigator-initiated pilot clinical trial to compare the effect } \\
\text { of micro-particle curcumin versus placebo over } 24 \text { weeks in patients } \\
\text { who have chronic kidney disease. This study will monitor and } \\
\text { determine the safety and efficacy of curcumin relative to placebo in } \\
\text { reducing albuminuria, urinary IL-18, and the loss of eGFR. }\end{array}$ \\
\hline $\begin{array}{l}\text { Micellar Curcumin and Metabolic Syndrome Biomarkers } \\
\text { (NCT01925547) Phase } 2 \text { (recruiting); University of Hohenheim } \\
\text { and German Federal Ministry of Education and Research, } \\
\text { Germany. }\end{array}$ & $\begin{array}{l}\text { To evaluate metabolic profiles upon oral treatment of micellar } \\
\text { curcumin, i.e., C-reactive protein, plasma curcumin concentrations, } \\
\text { serum alanine transaminase activity, blood glucose, TNF- } \alpha \text {, serum } \\
\text { uric acid, serum total cholesterol, serum triacylglycerols, cholester } \\
\text { ol, serum aspartate transaminase activity, gamma-glutamyl trans } \\
\text { ferase activity, alkaline phosphatase activity, bilirubin, IL-6, body } \\
\text { weight, and diastolic/systolic blood pressure, etc. }\end{array}$ \\
\hline
\end{tabular}

$e G F R$ estimated glomerular filtration rate, $H D / L D L$ high-density/low-density lipoprotein, $I L$ interleukin, $T N F-\alpha$ tumor necrosis factor alpha

usually happens just after angioplasty, organ transplantation, or stent implantation. Cardiovascular medicine, such as the statins, efficiently blocks migration of VSMCs. Wang et al. (62) designed a self-assembled amphiphilic carbomethylhexanol chitosan nanomatrix with curcumin, which manipulates the cellular internalization and low-dose sustained and controlled cytotoxic effect on growth and migration of VSMCs. Doxorubicin hydrochloride (DOX) is a first-line chemotherapy, but this therapy is highly associated with severe cardiotoxicity. This side effect can be mitigated by co-administration of the pluronic loaded nanocurcumin formulation by reducing apoptosis and reactive oxygen species (ROS) levels (63). Pramanik et al. (64) further confirmed that a nanocurcumin formulation could overcome multidrug resistance in cancer cells and ameliorate doxorubicin-associated cardiomyopathy by reducing DOXinduced intracellular oxidative stress (an indicative of total glutathione levels and glutathione peroxidase activity) in cardiac tissue. Angiogenesis plays a crucial role in atherosclerosis and other cardiovascular diseases and has emerged as a major vague issue (65). The curcumin in poly(ester amine) nanoparticles efficiently inhibited angiogenesis in a transgenic zebra fish model, representing a novel antiangiogenesis therapy (66).

\section{Neurodegenerative, Alzheimer's, and Brain Diseases}

Many human diseases evolve in the central nervous system (CNS), brain, or the spinal cord. Delivery of curcumin at these sites requires overcoming complexity of the bloodbrain barrier (BBB). A promising strategy is to functionalize apolipoprotein E (ApoE)-derived peptides (residues 141150) to nanoparticles (67).

Alzheimer's disease (AD) progresses with the accumulation of $\beta$-amyloid peptide $(A \beta)$ in senile plaques, which is toxic to species in monomeric and fibrillary form and is a hallmark lesion of AD. Curcumin is a molecule that can target the amyloid pathology, and therefore, delivery of curcumin has received great attention, and its imaging capacity offers diagnostic capabilities. Biodegradable PLGA-curcumin nanoformulations exhibit nontoxicity in human neuroblastoma SK-N-SH cells and protect $\mathrm{H}_{2} \mathrm{O}_{2}$ induced elevation of ROS. This formulation is able to prevent the induction of the redox-sensitive transcription factor Nrf2 
Table IV. Evaluation of Targeted Curcumin Nanoformulations for Cancer Therapeutics

Details of article
Transferrin (TF)-mediated solid lipid nanoparticles (54)
Transferrin-targeted polymeric micelles co-loaded with curcumin
and paclitaxel (55)

Anti-PSMA conjugated curcumin loaded PLGA NPs (30)

Folic acid conjugated cross-linked acrylic polymer hydrogel (56)

Multifunctional targeting nano-carrier drug delivery system based on CD44 receptor and tumor microenvironment $\mathrm{pH}$ condition (57)

Magnetic core-shell nanocapsules with dual-targeting capabilities and co-delivery of multiple drugs to treat brain gliomas (58)

Enhancement of cellular uptake and cytotoxicity of curcuminloaded PLGA nanoparticles by conjugation with anti-Pglycoprotein (59)

Folate decorated dual drug loaded nanoparticle: role of curcumin in enhancing therapeutic potential of nutlin-3a (22)

Surface functionalization of PLGA nanoparticles by noncovalent insertion of a homo-bifunctional spacer (60)

Multistage polymeric micelles based on amphiphilic poly $(\beta$-amino ester) derivatives (61)
Description of results

TF-tagged curcumin nanoformulations show a 5-fold increased uptake by MCF-7 cancer cells. This formulation induces $44.5 \%$ apoptosis compared to curcumin nanoparticles $(32.4 \%)$ at $10 \mu \mathrm{M}$.

TF-targeted combination polymer micelles induce significant cytotoxic effect of curcumin and paclitaxel. A constant curcumin nanoformulation ( 5 and $10 \mu \mathrm{M}$ ) was able to reduce the paclitaxelrequired IC50 concentration from $\sim 1.78$ and $0.68 \mu \mathrm{M}$ to $\sim 0.74$ and $0.1 \mu \mathrm{M}$.

PSMA-targeted curcumin-loaded nanoparticles target only PSMAexpressing cancer cells both in vitro and in vivo. This formulation also exhibits superior anti-cancer effects against prostate cancer cells compared to native curcumin and its nanoformulation.

This curcumin nanoformulation showed higher cellular uptake in human cervical cancer cell lines than the nonfolate conjugated form.

The anti-tumor activity of the targeted nanoformulation was most efficient in suppressing tumor growth in an animal model.

The combinational effects, i.e., curcumin in nanoformulation, magnetic guidance, and targeting lactoferrin receptor, have been maximal in brain tumor-bearing mice not only achieving high accumulation, but also efficiently suppressing cancer growth, either curcumin alone or in combination with doxorubicin.

Anti-Pgp-conjugated curcumin nanoparticles exhibit superior cellular uptake by KB-V1 cells and thus enhance cytotoxicity.

Folate-targeted curcumin nanoformulations are capable of inducing enhanced expression of proapoptotic, down-regulation of antiapoptotic proteins, and down-regulation of $\mathrm{bcl} 2$ and $\mathrm{NF}-\kappa \mathrm{B}$ gene/protein.

This novel surface-modified targeted nanoformulation internalizes more in annexin A2-positive cells than in negative cells.

$\mathrm{pH}$-responsive curcumin micelles are proven to have enhanced cancer growth inhibition $(65.6 \%)$ ability.

TF transferrin, PLGA poly(lactide-co-glycolide) PSMA prostate-specific membrane antigen, $M C F-7$ Michigan Cancer Foundation-7 breast cancer cell line, $N F-\kappa B$ nuclear factor kappa B, IC50 half maximal inhibitory concentration, $N P$ nanoparticle

in the presence of $\mathrm{H}_{2} \mathrm{O}_{2}$, indicative strategy to protect neurons against oxidative damage that is commonly observed in $\mathrm{AD}$ (68). Additionally, curcumin formulations containing biotin coupling poly(ethylene glycol)ylated (PEGylated), biodegradable poly(alkyl cyanoacrylate) (69), PEG liposomes with the anti-transferrin (70), lipid conjugate liposome (71), nanoliposomes (72), PEG-polylactic acid block co-polymer (72), and click-chemistry-based nanoliposomes (73) have shown aggregation inhibition of $A \beta$ and toxicity rescue of $\mathrm{A} \beta$, indicative of $\mathrm{AD}$ treatment and diagnosis. Another important study using NanoCurc ${ }^{\mathrm{TM}}$ formulation revealed that decreased levels of $\mathrm{H}_{2} \mathrm{O}_{2}$, increased level of glutathione, and decreased levels of caspase 3 and caspase 7 activities in athymic mice brain suggest a favorable redox intracellular environment worthy of implementation of this treatment for AD (74). In addition, ApoE3-conjugated and curcuminloaded PBCA polymer nanoparticles offer a great advantage in the treatment of $A \beta$-induced cytotoxicity in AD (75). Curcumin functionalized gold nanoparticles efficiently interact with amyloid protein/peptide and simultaneously inhibit amyloid fibrillation and dissolve amyloid fibrils by acting as artificial molecular chaperones (76).

An adverse effect of aluminum $\left(\mathrm{AlCl}_{3}\right.$, neurotoxicant) was completely reversed by an oral administration of lipid nanoformulation of curcumin in male Lacca mice (77) that resulted in a $97 \%$ recovery in membrane lipids and $73 \%$ recovery in acetylcholinesterase. Similarly, neurotoxicity induced by acrolein can be reversed by using PLGA-based curcumin nanoformulations. This reversal was achieved by restoring the expression of $\gamma$-glutamylcysteine synthetase, ROS, and reactive nitrogen species levels but had no effect on the decrease of glutathione display neuroprotection (78).

A novel approach of superparamagnetic iron oxide conjugated with curcumin demonstrated that amyloid plaques could be visualized in ex vivo magnetic resonance imaging (MRI) in $\operatorname{Tg} 2576$ mouse brains and no plaque was found in nontransgenic mice (79). Significant accumulation and colocalization of nanoparticles with amyloid plaques were observed in immunohistochemical examination of the mouse brains. Therefore, this formulation has great potential for noninvasive diagnosis of AD using MRI over positron emission tomography (PET) scan imaging. Anti-amyloid antibody-conjugated and curcumin/dexamethasone-loaded gadolinium/magnetic nanoparticles are ideal for early diagnosis, effective targeting, and as therapeutic agent(s) of cerebrovascular amyloid (80).

Mitochondrial dysfunctions cause numerous human disorders, including Huntington's disease. Attenuation of 
mitochondrial impairments could provide a potential therapeutic intervention for this disease. In vitro screening of a library of charge- and size-varied formulation of PLGA-bPEG-triphenylphosphonium polymer (PLGA- $b$-PEG-TPP)based curcumin nanoformulation confirms significant cytosolic and mitochondrial fractions in cells, indicating mitochondria-targeting chemotherapeutics (81). Another solid-lipid-based curcumin nanoformulation attenuates 3nitropropionic-acid-induced Huntington's disease in rats by increasing complex II activity, restoring the glutathione and superoxide dismutase (82). Intervention of ameliorated mitochondrial dysfunctions in HD was also due to the reduction in mitochondrial swelling, lipid peroxidation, protein carbonyls, and reactive oxygen species (82).

\section{Stroke}

Stroke causes irreversible deterioration of the CNS due to interruption of blood, oxygen, and nutrient supply. Curcumin may limit the risk for stroke by lowering cholesterol, limiting the clogging of arteries, and acting as blood thinning agent. A proof-of-concept study in Balb/c mice confirms that bioavailability is 32-1555 times higher, pharmacodynamics is $3-4$ times higher, and brain targeting is 8.135 times higher when curcumin is used in the form of solid lipid nanoparticles (83) for stroke treatment. Such efficient targeting can be verified using a sensitive method employing liquid chromatography coupled with tandem mass spectrometry for the simultaneous determination of curcumin in mouse plasma and brain tissue, using salbutamol as an internal standard (84). Ramalingam et al. (85) proposed an oral curcumin nanoformulation from $N$-trimethyl chitosan surface-modified solid lipids for successful brain distribution of curcumin. Poly( $N$-isopropyl acrylamide)-curcumin nanoformulation has shown improved neurobehavioral activity and reduced cytokine levels (tumor necrosis factor alpha $(\mathrm{TNF}-\alpha)$ and IL-1 $\beta$ ) in middle cerebral artery occlusioninduced cerebral ischemic rats (86). This formulation is also capable of reducing oxidative stress-associated brain injury after middle cerebral artery occlusion in rats (87). The efficacy of this formulation was assessed by grip strength, locomotor activity, and biochemical studies in the brain. A recent study by Kalani et al. (88) demonstrated the role of curcumin encapsulated in exosomes with $200 \mathrm{~nm}$ size as an epigenetic agent in cerebral stroke. Another efficient solid lipid nanoparticle of curcumin alleviates behavioral, oxidative, and nitrosative stress; acetylcholinesterase; and mitochondrial enzyme complexes, and physiological parameters in cerebral ischemic reperfusion injury in rats (89) indicate its protective role against cerebral ischemic insult.

\section{Inflammatory Diseases}

Inflammation is the body's protective biological response to harmful injury or infection. There are more than dozen inflammatory-related disorders. Monocyte-derived myeloid cells help to fight against inflammation-related infections. Curcumin has been proven to have anti-inflammatory, antioxidation, and neuro-protective properties. Nanotized formulation of curcumin successfully inhibits lipopolysaccharide
(LPS)-induced inflammation in rat model (90). At the same time, the employed concentration does not cause adverse effects as measured by blood and brain lactic acid concentrations, kidney function, and neuronal apoptosis. Another PLGA-Eudragit $\left({ }^{\circledR}\right)$ S100-based curcumin nanoformulation significantly reduced TNF- $\alpha$ secretion by LPS-activated macrophages (J774 cells) (91). In in vivo studies, this formulation also minimized neutrophil infiltration and TNF$\alpha$ discharge in a murine dextran sulfate sodium-induced colitis model. indicating that it is a suitable treatment approach for inflammatory bowel disease (IBD). Shukla et al. (92) proved that nanoemulsion of curcumin in rats exhibited LPS-induced lung- and liver-associated injury due to minimizing neutrophil migration, reducing TNF- $\alpha$ levels, and oxidative stress. Exosome-mediated curcumin delivery can be efficient to activate myeloid cells in vivo (in a lipopolysaccharide (LPS)induced septic shock mouse model) (93).

A novel nanocarrier transdermal gel curcumin nanoformulation was designed against inflammation and was determined to be nonirritant (skin irritation scored 0.49) and safe for human use (94). This may be developed as a treatment modality for localized inflammation. Curcumin-loaded solid lipid nanoparticles effectively reduced levels of IL-1 $\beta$ expression and decreased expression of serum proinflammatory cytokines (IL-6, TNF- $\alpha$, and IL-1 $\beta$ ), anti-inflammatory (cyto-

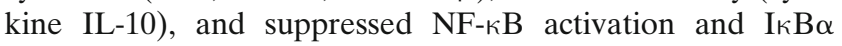
degradation levels, suggesting its role in treating sepsis (95). A synergistic action of the drug combination of celecoxib and curcumin nanoformulation was achieved in an ulcerative colitis model in rats (96). In addition, curcumin-loaded solid nanoparticles have also been tested for hepatoprotection (97). This has been confirmed by examining the following: (i) extent of liver damage and repair, (ii) levels of alanine aminotransferase and aspartate aminotransferase, (iii) oxidative stress markers (malondialdehyde, superoxide dismutase, and reduced glutathione), and (iv) TNF- $\alpha$, in a carbon tetrachloride-induced hepatic injury rat model.

Rheumatoid arthritis is a chronic inflammatory disease occurring in joints and cartilages. Arora et al. (98) established an effective curcumin-loaded solid lipid nanoparticle utility in complete Freund's adjuvant-induced arthritis rat model. The results in arthritic rat model showed a significant increase in (i) blood leukocyte count, (ii) oxidative-nitrosative stress, (iii) TNF- $\alpha$ and C-reactive protein, (iv) cyclic citrullinated peptide antibody levels, and (v) radiological alterations, which support protective effects against arthritis.

\section{Diabetes}

Diabetes is an indication found in humans in which blood glucose levels are high. Curcumin has been effective against diabetes-related complications, including heart, kidney, and liver disease. Therefore, it is believed that delivering curcumin in the form of nanoparticles and lipid/liposomes could improve therapeutic outcomes (99). Selfnanoemulsifying drug delivery system containing curcumin was evaluated in male Sprague-Dawley rats for diabetic neuropathy (100), and the results showed greater neuroprotective function as confirmed by various parameters such as nerve function and inflammatory proteins (NF- $\kappa \mathrm{B}$, IKK- $\beta$, COX-2, iNOS, TNF- $\alpha$, and IL-6). Diabetes is also linked to 
increased levels of free radicals and systemic proinflammatory cytokines that can alter lipid profiles. In a recent study, an employed PLGA-curcumin nanoformulation in streptozotocin-induced diabetic rats demonstrated reduced C-reactive protein levels, IL-6, and TNF that lead to significant reduction in plasma triglycerides and total cholesterol and an increase in high-density lipoprotein cholesterol (101). In a leptin-deficient (ob/ob) mouse with steatosis model of insulin resistance, treatment with liposome nanoparticles inhibited proinflammatory pathways in hepatic tumor necrosis factor, inducible nitric oxide synthaseproducing dendritic cells, and adipose tissue macrophages (ATMs), which can reverse insulin resistance, an indication for targeting inflammatory approach for type 2 diabetes (102).

\section{Lung Diseases}

Inflammation is an ultimate event in the development of lung diseases, including asthma, chronic obstructive pulmonary disease, severe acute respiratory syndrome, lung cancer, granulomatous lung diseases, and so on. The effective delivery of curcumin to the lung depends on the physiology of the lungs and a number of factors such as type of formulation, mode of delivery, and its mode of action. Conventional poly(lactic acid) (PLA)containing curcumin showed an improvement in the antiinflammatory activity of curcumin even at $1 / 8$ dose, i.e., 50 vs. $400 \mathrm{mg} / \mathrm{kg}$ free curcumin (103). A self-assembled anisotropic (Janus particles) curcumin formulation delivered through local inhalation in an orthotopic mouse model of human lung cancer resulted in accumulation and retention of most of the nanoparticles in the lungs of mice for at least $24 \mathrm{~h}$ for inducing its effects (104).

Upon administering curcumin solid lipid nanoparticles in mice, maximum nanoparticles reached the lung and liver (105). More importantly, in ovalbumin-induced allergic rat model of asthma, this formulation effectively (i) suppressed airway hyperresponsiveness, (ii) suppressed inflammatory cell infiltration, and (iii) inhibited the expression of T-helper-2-type cytokines (IL-4 and IL-13) in bronchoalveolar lavage fluid, indicative of a promising candidate for asthma therapy (105). The more popular curcumin formulation, NanoCurc ${ }^{\mathrm{TM}}$, can maintain intrahepatic curcumin levels in hepatocytes and nonparenchymal cells, which can help to inhibit carbon tetrachloride-induced liver injury (38). Another study confirmed significant anti-inflammatory activities of curcumin-loaded polyvinylpyrrolidone induction in the lung epithelial cells of TNF- $\alpha$-treated mice (106).

Delivering drugs to the small airways, terminal bronchioles, and deep lung is difficult. A chitosan-based curcumin nanoparticle formulation delivers effectively to the deep lung via extratesticular Sertoli cells (107). These swellable hydrogel-based microparticle pressurized metered dose inhaler formulations can also be used as potential delivery vehicles for nanoparticle therapeutics. (108). Inhibition of methicillin-resistant Staphylococcus aureus (MRSA) in in vitro and in vivo (MRSA-induced pneumonia in mice) was achieved by upconversion of near infrared light nanoparticles conjugated with curcumin due to activated effects under NIR photosensitizer (109).

\section{Anti-Microbial and Wound Healing}

Curcumin has been known for centuries as a household remedy that can be extended to anti-microbial activity (110). In addition, curcumin has proven wound healing properties which helps in enhanced granulation tissue formation, collagen deposition, tissue remodeling, and wound contraction (111). An aqueous dispersion of wet milling nanocurcumin exhibited potent activity against a number bacteria (S. aureus, Bacillus subtilis, Escherichia coli, Pseudomonas aeruginosa, Penicillium notatum, and Aspergillus niger); however, it was more effective against Gram-positive bacteria than Gram-negative bacteria (112). Curcumin nanovesicles efficiently bind to the surface of bacteria and reduce their counts from $5 \log \mathrm{CFU} \mathrm{mL} \mathrm{m}^{-1}$ to an undetectable level, suggesting a novel approach for controlling microbial growth, cross-contamination, and biofilm formation (113).

A high curcumin-loaded and biodegradable in situ gel formulation is capable of inducing well tissue adhesiveness and releasing curcumin in a sustained manner that is suitable for wound healing application (114). This formulation proved to have in vivo wound healing activity that was determined by higher tensile strength and thicker epidermis. In addition, this gel formulation confirmed an increase in collagen content, granulation, wound maturity, and catalase while a decrease in superoxide dismutase. In a recent study, curcuminencapsulated nanoparticles exhibited a dose-dependent inhibition of methicillin-resistant $S$. aureus and P. aeruginosa (115). The same formulation showed inhibited MRSA growth and enhanced wound healing activity in a murine wound model. A combination of curcumin nanoparticles with silver and chitosan formulation was successful in eradicating parasite from stool and intestine in Giardia lamblia cyst rat model (116). More importantly, this treatment did not show any signs of nondesirable toxicity.

\section{Ophthalmic}

Beneficial effects of curcumin on several ocular diseases, including dry eye syndrome, glaucoma, age-related macular degeneration, and diabetic retinopathy suggest its implementation for ophthalmology (117). Initial studies were confirmed that curcumin in albumin or pluronic polymers (F127 and F68) have sol-gel transition with sustained curcumin release characteristics and were found to have no eye irritation in rats (118). This work prompted implementation for its ocular application. Pradhan et al. (119) successfully proved that retention of curcumin in the cornea can be accomplished with curcumin-loaded PEG-PCL nanoparticles. Curcumin formulation also suppressed the expression of vascular endothelial growth factor, inflammatory cytokines, and matrix metalloproteinases. Altogether, this study confirms a potential approach for prevention of corneal neovascularization.

\section{Skin Diseases}

Curcumin has been used since ancient ages as a beauty product, which suggests its implication in skin-related diseases. A $\beta$-cyclodextrin-curcumin nanoparticle complex improved permeability across skin model tissue in gel form 1.8- 
fold over the free CUR gel (120). Another curcumin encapsulated in PVA nanoformulation showed no improved penetration in pig skin dermis via hair follicle (121). Ethyl cellulose and methylcellulose blended curcumin nanoparticles can be used to transport curcumin effectively into the porcine ear skin (122). Biocompatible curcumin-loaded phospholipid vesicles can counteract on phorbol ester 12-Otetradecanoylphorbol-13-acetate (TPA)-induced lesions and inflammation (123). This was confirmed by an extensive reepithelization of the TPA-damaged skin. Additionally, this formulation was proven to form skin lesion abrogation, which causes epithelial loss and skin damage. Furthermore, an encapsulated curcumin nanoparticle formulation penetrates into the skin and subsequently reduces UVB-irradiationinduced radical formation more than free curcumin (124).

\section{Malaria}

The World Health Organization estimates that about half- a million deaths occur due to malaria, which is caused by a parasite called Plasmodium (transmitted via the bites of infected mosquitoes). Parenteral administration of lipid-based curcumin nanoparticles in an in vivo model resulted in a 2fold increase in anti-malarial activity over free curcumin (125). Furthermore, a novel PEGylated liposome-based curcumin nanoformulation provided the most pronounced and statistically significant therapeutic benefit in in vivo Plasmodium berghei NK-65-infected (murine model of malaria) mice (126). Chitosan-bound curcumin nanoformulation inhibited hemozoin synthesis, which is lethal for the parasite (127) suggesting its anti-malarial activity. The mice infected with a lethal strain survive for five more days upon treatment with this nanoformulation.

\section{Cystic Fibrosis}

Cystic fibrosis is also a common life-threatening disease and has evolved mainly due to mutations in the gene encoding (primarily $\Delta \mathrm{F} 508$ ) the cystic fibrosis transmembrane conductance regulator (CFTR), which causes retention of $\Delta F 508-C F T R$ in the endoplasmic reticulum and frontrunners for absence of CFTR $\mathrm{Cl}(-)$ channels. This phenomenon can be corrected by curcumin treatment $(128,129)$. A PLGAbased curcumin nanoparticle formulation has been able to correct the defects associated with cystic fibrosis in two different mouse strains (130). A formulation with a blend of PLGA- $b$-PEG-triphenylphosphonium is capable of targeting mitochondria and demonstrates its adaptability for mitochondrial-associated diseases (81).

\section{Osteoporosis}

Cyclodextrin-conjugated gold nanoparticles selfassembled with curcumin formulation significantly inhibited osteoclast formation of bone marrow-derived macrophages via suppression of the receptor activator of nuclear factor- $\kappa \mathrm{B}$ ligand-induced signaling pathway (131). The in vivo results in an ovariectomy-induced osteoporosis model demonstrate that this formulation improved bone density and prevented its loss.

\section{Human immunodeficiency virus (HIV)}

Incompatibility of rigid implants and the soft brain tissue results in oxidative stress that leads to the neurodegenerative reactive tissue response. Curcumin-releasing softening polymer implants not only cause minimal implant neuroinflammation but also utilize a new concept of localized curcumin delivery (132). Sankar et al. (133) further proved that curcumin nanoformulation significantly decreased the lipid peroxidation and increased the enzymatic and nonenzymatic anti-oxidants (glutathione content, superoxide dismutase, catalase, glutathione peroxidase, and glutathione reductase) in brain and prevented arsenic-induced oxidative damage. A simple and direct nose-to-brain delivery of curcumin nanoformulation with poly( $N$-isopropyl acrylamide) has been developed (134). Gandapu et al. (135) developed apotransferrin tagged curcumin nanoparticles by sol-oil chemistry for improved uptake in $\mathrm{T}$ cells through transferrin-mediated endocytosis, which shows a higher antiHIV activity nanocurcumin ( $\mathrm{IC}(50)<1.75 \mu \mathrm{M})$ compared to sol-curcumin $(\operatorname{IC}(50)=5.1 \mu \mathrm{M})$. This is attributed to prominent inhibition of HIV-1-induced expression of Topo II $\alpha$, IL$1 \beta$, and COX-2 and blocking the synthesis of viral cDNA in the gag region.

\section{EXPERT OPINION}

Although curcumin is a food additive that is widely consumed worldwide on daily basis, there are concerns about its bioavailability, a suboptimal pharmacokinetics, and minor side effects. It is important to improve these features and overcome those unforeseen side effects by encapsulating or by adding ingredients or excipients that help curcumin's overall stability. However, an investigational new drug application is required for conducting any clinical trials. Since parent curcumin is widely consumed by humans, there may not be any major restriction by USFDA. Food-based curcumin nanotechnology is likely to be approved as an alternative therapeutic modality in the near future and may have a significant impact in daily lifestyles. The clinical translation of curcumin nanoformulations can be possible with expertise from various disciplines, e.g., biologists, nanotechnologists, pharmaceutical scientists, and pre-clinical and clinical personnel. However, the goal is that such renewed interest in curcumin nanotherapeutic approaches will lead toward generation of new formulations for various disease treatments with minimal adverse effects.

The overall aim of the development of curcumin nanoformulations is to either prevent or slow down the development, which potentially lowers the incidence and burden, of disease. It is also important to understand the molecular mechanisms of curcumin nanoformulations in addition to the native curcumin molecule. It is also advised to examine and compare the therapeutic outcome of curcumin nanoformulations with the existing conventional therapeutic modality.

A comparative mechanistic approach should be implemented to learn how these curcumin nanoformulations enhance the therapeutic activity and control the progression, recurrence, metastases, and disorder of diseases. All these preliminary examinations will be helpful in identifying a 
suitable curcumin nanoformulation that has predicted optimal loading, release, and targeting capacity. Many physiological barriers certainly hinder the penetration of curcumin nanoformulations deep inside the disease area and performance of its activities. Often, such circumstances lead to limited drug supply and accumulation, which cause cells to develop resistance. In the case of a highly fibrotic condition, design of curcumin nanoformulations composed of collagen or fibrotic tissue dissolution agent/inhibitors or tumorpenetrating peptides along with an antibody-guided targeted manipulation helps to deliver curcumin deep into disease tissue in a step-wise manner. Additionally, recent developments have revealed that multiple drugs or a drug with siRNA/miRNA molecule delivery through nanoparticles modulates the microenvironment and offers a better therapeutic index. Therefore, developing such novel composite systems would help to improve patient compliance by reducing side effects and increasing potential benefits.

\section{CONCLUSION}

Curcumin is an inexpensive polyphenol extracted compound from curcuma longa that is abundantly available and nontoxic with exhibited medicinal opportunities. A number of in vitro, in vivo, and clinical trial investigations have provided evidence for the bioactive role of curcumin in the prevention and treatment of various human diseases. Several curcumin nanoformulations discussed in this review efficiently tackle various signaling pathways that are linked to various human diseases. Most of these studies have been conducted only in pre-clinical animal models, and therefore, a main shortcoming is our lack of understanding of curcumin nanoformulation risks in humans. Clinical trials confirm that curcumin nanoformulations improve curcumin bioavailability and are systemically safe. However, testing of these formulations as therapeutic modalities is highly desirable and is crucial for future clinical trials and for human use. In addition, implementation of curcumin nanoformulations as combination agents is appropriate for reducing the dose of the main therapeutic agent, which can result in enhanced therapeutic efficacy while reducing systemic toxicity.

\section{ACKNOWLEDGMENTS}

The authors thank Cathy Christopherson for editorial support. This work was partially supported by grants from the National Institutes of Health Research Project Grant Program (K22 CA174841, U01 CA142736, R01CA142736) and Department of Defense ARMY GRANT W81XWH-14-10154 .

Conflict of Interest Authors declared no conflicts of interest.

\section{REFERENCES}

1. Aggarwal BB, Sundaram C, Malani N, Ichikawa H. Curcumin: the Indian solid gold. Adv Exp Med Biol. 2007;595:1-75. doi:10.1007/978-0-387-46401-5_1.
2. Maheshwari RK, Singh AK, Gaddipati J, Srimal RC. Multiple biological activities of curcumin: a short review. Life Sci. 2006;78(18):2081-7. doi:10.1016/j.lfs.2005.12.007.

3. Trujillo J, Chirino YI, Molina-Jijon E, Anderica-Romero AC, Tapia E, Pedraza-Chaverri J. Renoprotective effect of the antioxidant curcumin: recent findings. Redox Biol. 2013;1:44856. doi:10.1016/j.redox.2013.09.003.

4. Burgos-Moron E, Calderon-Montano JM, Salvador J, Robles A, Lopez-Lazaro M. The dark side of curcumin. Int J Cancer J Int du Cancer. 2010;126(7):1771-5. doi:10.1002/ijc.24967.

5. Anand P, Kunnumakkara AB, Newman RA, Aggarwal BB. Bioavailability of curcumin: problems and promises. Mol Pharm. 2007;4(6):807-18. doi:10.1021/mp700113r.

6. Yang CS, Sang S, Lambert JD, Lee MJ. Bioavailability issues in studying the health effects of plant polyphenolic compounds. Mol Nutr Food Res. 2008;52 Suppl 1:S139-51. doi:10.1002/ mnfr.200700234.

7. Yallapu MM, Jaggi M, Chauhan SC. Curcumin nanoformulations: a future nanomedicine for cancer. Drug Discov Today. 2012;17(1-2):71-80. doi:10.1016/ j.drudis.2011.09.009.

8. Gupta SC, Patchva S, Aggarwal BB. Therapeutic roles of curcumin: lessons learned from clinical trials. AAPS J. 2013;15(1):195-218. doi:10.1208/s12248-012-9432-8.

9. Gupta SC, Sung B, Kim JH, Prasad S, Li S, Aggarwal BB. Multitargeting by turmeric, the golden spice: from kitchen to clinic. Mol Nutr Food Res. 2013;57(9):1510-28. doi:10.1002/ mnfr.201100741.

10. Yallapu MM, Jaggi M, Chauhan SC. Curcumin nanomedicine: a road to cancer therapeutics. Curr Pharm Des. 2013;19(11):1994-2010.

11. Ghalandarlaki N, Alizadeh AM, Ashkani-Esfahani S. Nanotechnology-applied curcumin for different diseases therapy. BioMed Res Int. 2014;2014:394264. doi:10.1155/2014/ 394264.

12. Naksuriya O, Okonogi S, Schiffelers RM, Hennink WE. Curcumin nanoformulations: a review of pharmaceutical properties and preclinical studies and clinical data related to cancer treatment. Biomaterials. 2014;35(10):3365-83. doi:10.1016/ j.biomaterials.2013.12.090.

13. Bansal SS, Goel M, Aqil F, Vadhanam MV, Gupta RC. Advanced drug delivery systems of curcumin for cancer chemoprevention. Cancer Prev Res. 2011;4(8):1158-71. doi:10.1158/1940-6207.CAPR-10-0006.

14. Sun M, Su X, Ding B, He X, Liu X, Yu A, et al. Advances in nanotechnology-based delivery systems for curcumin. Nanomedicine. 2012;7(7):1085-100. doi:10.2217/nnm.12.80.

15. Yallapu MM, Ebeling MC, Jaggi M, Chauhan SC. Plasma proteins interaction with curcumin nanoparticles: implications in cancer therapeutics. Curr Drug Metab. 2013;14(4):504-15.

16. Flora G, Gupta D, Tiwari A. Nanocurcumin: a promising therapeutic advancement over native curcumin. Crit Rev Ther Drug Carrier Syst. 2013;30(4):331-68.

17. Lee WH, Loo CY, Young PM, Traini D, Mason RS, Rohanizadeh R. Recent advances in curcumin nanoformulation for cancer therapy. Expert Opin Drug Deliv. 2014;11(8):1183201. doi:10.1517/17425247.2014.916686.

18. Kanai M, Imaizumi A, Otsuka Y, Sasaki H, Hashiguchi M, Tsujiko K, et al. Dose-escalation and pharmacokinetic study of nanoparticle curcumin, a potential anticancer agent with improved bioavailability, in healthy human volunteers. Cancer Chemother Pharmacol. 2012;69(1):65-70. doi:10.1007/s00280011-1673-1.

19. Petros RA, DeSimone JM. Strategies in the design of nanoparticles for therapeutic applications. Nat Rev Drug Discov. 2010;9(8):615-27. doi:10.1038/nrd2591.

20. Torchilin VP. Multifunctional, stimuli-sensitive nanoparticulate systems for drug delivery. Nat Rev Drug Discov. 2014;13(11):813-27. doi:10.1038/nrd4333.

21. Gunasekaran T, Haile T, Nigusse T, Dhanaraju MD. Nanotechnology: an effective tool for enhancing bioavailability and bioactivity of phytomedicine. Asian Pac J Trop Biomed. 2014;4 Suppl 1:S1-7. doi:10.12980/APJTB.4.2014C980.

22. Das M, Sahoo SK. Folate decorated dual drug loaded nanoparticle: role of curcumin in enhancing therapeutic 
potential of nutlin-3a by reversing multidrug resistance. PLoS One. 2012;7(3), e32920. doi:10.1371/journal.pone.0032920.

23. Scarano W, Souza P, Stenzel MH. Dual-drug delivery of curcumin and platinum drugs in polymeric micelles enhances the synergistic effects: a double act for the treatment of multidrug-resistant cancer. Biomater Sci. 2015;3:163-74.

24. Tiyaboonchai W, Tungpradit W, Plianbangchang P. Formulation and characterization of curcuminoids loaded solid lipid nanoparticles. Int J Pharm. 2007;337(1-2):299-306. doi:10.1016/ j.ijpharm.2006.12.043.

25. Mulik R, Mahadik K, Paradkar A. Development of curcuminoids loaded poly(butyl) cyanoacrylate nanoparticles: physicochemical characterization and stability study. Eur J Pharm Sci: Off J Eur Fed Pharm Sci. 2009;37(3-4):395-404. doi:10.1016/ j.ejps.2009.03.009.

26. Onoue S, Takahashi H, Kawabata Y, Seto Y, Hatanaka J, Timmermann B, et al. Formulation design and photochemical studies on nanocrystal solid dispersion of curcumin with improved oral bioavailability. J Pharm Sci. 2010;99(4):1871-81. doi:10.1002/jps.21964.

27. Yallapu MM, Jaggi M, Chauhan SC. beta-Cyclodextrincurcumin self-assembly enhances curcumin delivery in prostate cancer cells. Colloids Surf B: Biointerfaces. 2010;79(1):113-25. doi:10.1016/j.colsurfb.2010.03.039.

28. Yallapu MM, Jaggi M, Chauhan SC. Poly(beta-cyclodextrin)/ curcumin self-assembly: a novel approach to improve curcumin delivery and its therapeutic efficacy in prostate cancer cells. Macromol Biosci. 2010;10(10):1141-51. doi:10.1002/ mabi.201000084.

29. Ranjan AP, Mukerjee A, Helson L, Vishwanatha JK. Scale up, optimization and stability analysis of curcumin C3 complexloaded nanoparticles for cancer therapy. J Nanobiotechnology. 2012;10:38. doi:10.1186/1477-3155-10-38.

30. Yallapu MM, Khan S, Maher DM, Ebeling MC, Sundram V, Chauhan $\mathrm{N}$, et al. Anti-cancer activity of curcumin loaded nanoparticles in prostate cancer. Biomaterials. 2014;35(30):8635-48. doi:10.1016/j.biomaterials.2014.06.040.

31. Nagahama K, Sano Y, Kumano T. Anticancer drug-based multifunctional nanogels through self-assembly of dextrancurcumin conjugates toward cancer theranostics. Bioorg Med Chem Lett. 2015. doi:10.1016/j.bmcl.2015.04.062.

32. Zou P, Helson L, Maitra A, Stern ST, McNeil SE. Polymeric curcumin nanoparticle pharmacokinetics and metabolism in bile duct cannulated rats. Mol Pharm. 2013;10(5):1977-87. doi:10.1021/mp4000019.

33. Chiu SS, Lui E, Majeed M, Vishwanatha JK, Ranjan AP, Maitra A, et al. Differential distribution of intravenous curcumin formulations in the rat brain. Anticancer Res. 2011;31(3):907-11.

34. Bisht S, Feldmann G, Soni S, Ravi R, Karikar C, Maitra A, et al. Polymeric nanoparticle-encapsulated curcumin ("nanocurcumin"): a novel strategy for human cancer therapy. J Nanobiotechnology. 2007;5:3. doi:10.1186/14773155-5-3.

35. Lim KJ, Bisht S, Bar EE, Maitra A, Eberhart CG. A polymeric nanoparticle formulation of curcumin inhibits growth, clonogenicity and stem-like fraction in malignant brain tumors. Cancer Biol Ther. 2011;11(5):464-73.

36. Chun YS, Bisht S, Chenna V, Pramanik D, Yoshida T, Hong $\mathrm{SM}$, et al. Intraductal administration of a polymeric nanoparticle formulation of curcumin (NanoCurc) significantly attenuates incidence of mammary tumors in a rodent chemical carcinogenesis model: implications for breast cancer chemoprevention in at-risk populations. Carcinogenesis. 2012;33(11):2242-9. doi:10.1093/carcin/bgs248.

37. Bisht S, Mizuma M, Feldmann G, Ottenhof NA, Hong SM, Pramanik D, et al. Systemic administration of polymeric nanoparticle-encapsulated curcumin (NanoCurc) blocks tumor growth and metastases in preclinical models of pancreatic cancer. Mol Cancer Ther. 2010;9(8):2255-64. doi:10.1158/15357163.MCT-10-0172.

38. Bisht S, Khan MA, Bekhit M, Bai H, Cornish T, Mizuma M, et al. A polymeric nanoparticle formulation of curcumin (NanoCurc) ameliorates CCl4-induced hepatic injury and fibrosis through reduction of pro-inflammatory cytokines and stellate cell activation. Lab Investig J Tech Methods Pathol. 2011;91(9):1383-95. doi:10.1038/labinvest.2011.86.

39. Shutava TG, Balkundi SS, Vangala P, Steffan JJ, Bigelow RL, Cardelli JA, et al. Layer-by-layer-coated gelatin nanoparticles as a vehicle for delivery of natural polyphenols. ACS Nano. 2009;3(7):1877-85. doi:10.1021/nn900451a.

40. Prajakta D, Ratnesh J, Chandan K, Suresh S, Grace S, Meera $\mathrm{V}$, et al. Curcumin loaded $\mathrm{pH}$-sensitive nanoparticles for the treatment of colon cancer. J Biomed Nanotechnol. 2009;5(5):445-55.

41. Yallapu MM, Othman SF, Curtis ET, Gupta BK, Jaggi M, Chauhan SC. Multi-functional magnetic nanoparticles for magnetic resonance imaging and cancer therapy. Biomaterials. 2011;32(7):1890-905. doi:10.1016/j.biomaterials.2010.11.028.

42. Yallapu MM, Othman SF, Curtis ET, Bauer NA, Chauhan N, Kumar D, et al. Curcumin-loaded magnetic nanoparticles for breast cancer therapeutics and imaging applications. Int $\mathbf{J}$ Nanomedicine. 2012;7:1761-79. doi:10.2147/IJN.S29290.

43. Yallapu MM, Foy SP, Jain TK, Labhasetwar V. PEGfunctionalized magnetic nanoparticles for drug delivery and magnetic resonance imaging applications. Pharm Res. 2010;27(11):2283-95. doi:10.1007/s11095-010-0260-1.

44. Yallapu MM, Chauhan N, Othman SF, Khalilzad-Sharghi V, Ebeling MC, Khan S, et al. Implications of protein corona on physico-chemical and biological properties of magnetic nanoparticles. Biomaterials. 2015;46:1-12. doi:10.1016/ j.biomaterials.2014.12.045.

45. Manju S, Sreenivasan K. Gold nanoparticles generated and stabilized by water soluble curcumin-polymer conjugate: blood compatibility evaluation and targeted drug delivery onto cancer cells. J Colloid Interface Sci. 2012;368(1):144-51. doi:10.1016/ j.jcis.2011.11.024.

46. Singh DK, Jagannathan R, Khandelwal P, Abraham PM, Poddar P. In situ synthesis and surface functionalization of gold nanoparticles with curcumin and their antioxidant properties: an experimental and density functional theory investigation. Nanoscale. 2013;5(5):1882-93. doi:10.1039/c2nr33776b.

47. Manju S, Sreenivasan K. Enhanced drug loading on magnetic nanoparticles by layer-by-layer assembly using drug conjugates: blood compatibility evaluation and targeted drug delivery in cancer cells. Langmuir: ACS J Surf Colloids. 2011;27(23):14489-96. doi:10.1021/la202470k.

48. Anwar M, Asfer M, Prajapati AP, Mohapatra S, Akhter S, Ali $\mathrm{A}$, et al. Synthesis and in vitro localization study of curcuminloaded SPIONs in a micro capillary for simulating a targeted drug delivery system. Int J Pharm. 2014;468(1-2):158-64. doi:10.1016/j.ijpharm.2014.04.038.

49. Chen W, Xu N, Xu L, Wang L, Li Z, Ma W, et al. Multifunctional magnetoplasmonic nanoparticle assemblies for cancer therapy and diagnostics (theranostics). Macromol Rapid Commun. 2010;31(2):228-36. doi:10.1002/marc.200900793.

50. Rao W, Zhang W, Poventud-Fuentes I, Wang Y, Lei Y, Agarwal $\mathrm{P}$, et al. Thermally responsive nanoparticle-encapsulated curcumin and its combination with mild hyperthermia for enhanced cancer cell destruction. Acta Biomater. 2014;10(2):831-42.

51. Wang H, Yi J, Mukherjee S, Banerjee P, Zhou S. Magnetic/ NIR-thermally responsive hybrid nanogels for optical temperature sensing, tumor cell imaging and triggered drug release. Nanoscale. 2014;6(21):13001-11. doi:10.1039/c4nr03748k.

52. Patra S, Roy E, Karfa P, Kumar S, Madhuri R, Sharma PK. Dual-responsive polymer coated superparamagnetic nanoparticle for targeted drug delivery and hyperthermia treatment. ACS Appl Mater Interfaces. 2015;7(17):9235-46. doi:10.1021/ acsami.5b01786.

53. Sanoj Rejinold N, Thomas RG, Muthiah M, Chennazhi KP, Manzoor K, Park IK, et al. Anti-cancer, pharmacokinetics and tumor localization studies of $\mathrm{pH}-, \mathrm{RF}-$ and thermo-responsive nanoparticles. Int J Biol Macromol. 2015;74:249-62. doi:10.1016/j.ijbiomac.2014.11.044.

54. Mulik RS, Monkkonen J, Juvonen RO, Mahadik KR, Paradkar AR. Transferrin mediated solid lipid nanoparticles containing curcumin: enhanced in vitro anticancer activity by induction of apoptosis. Int J Pharm. 2010;398(1-2):190-203. doi:10.1016/ j.ijpharm.2010.07.021. 
55. Abouzeid AH, Patel NR, Sarisozen C, Torchilin VP. Transferrin-targeted polymeric micelles co-loaded with curcumin and paclitaxel: efficient killing of paclitaxel-resistant cancer cells. Pharm Res. 2014;31(8):1938-45. doi:10.1007/ s11095-013-1295-x.

56. Pillai JJ, Thulasidasan AK, Anto RJ, Chithralekha DN, Narayanan A, Kumar GS. Folic acid conjugated cross-linked acrylic polymer (FA-CLAP) hydrogel for site specific delivery of hydrophobic drugs to cancer cells. J Nanobiotechnology. 2014;12:25. doi:10.1186/1477-3155-12-25.

57. Chen D, Lian S, Sun J, Liu Z, Zhao F, Jiang Y, et al. Design of novel multifunctional targeting nano-carrier drug delivery system based on $\mathrm{CD} 44$ receptor and tumor microenvironment $\mathrm{pH}$ condition. Drug Deliv. 2014:1-6. doi: 10.3109/ 10717544.2014.917130.

58. Fang JH, Lai YH, Chiu TL, Chen YY, Hu SH, Chen SY. Magnetic core-shell nanocapsules with dual-targeting capabilities and co-delivery of multiple drugs to treat brain gliomas. Adv Healthc Mater. 2014;3(8):1250-60. doi:10.1002/ adhm.201300598.

59. Punfa W, Yodkeeree S, Pitchakarn P, Ampasavate C, Limtrakul P. Enhancement of cellular uptake and cytotoxicity of curcumin-loaded PLGA nanoparticles by conjugation with anti-P-glycoprotein in drug resistance cancer cells. Acta Pharmacol Sin. 2012;33(6):823-31. doi:10.1038/aps.2012.34.

60. Thamake SI, Raut SL, Ranjan AP, Gryczynski Z, Vishwanatha JK. Surface functionalization of PLGA nanoparticles by noncovalent insertion of a homo-bifunctional spacer for active targeting in cancer therapy. Nanotechnology. 2011;22(3):035101. doi:10.1088/0957-4484/22/3/035101.

61. Yu Y, Zhang X, Qiu L. The anti-tumor efficacy of curcumin when delivered by size/charge-changing multistage polymeric micelles based on amphiphilic poly(beta-amino ester) derivates. Biomaterials. 2014;35(10):3467-79. doi:10.1016/ j.biomaterials.2013.12.096.

62. Wang YJ, Lin HY, Wu CH, Liu DM. Forming of demethoxycurcumin nanocrystallite-chitosan nanocarrier for controlled low dose cellular release for inhibition of the migration of vascular smooth muscle cells. Mol Pharm. 2012;9(8):2268-79. doi:10.1021/mp300150q.

63. Carlson LJ, Cote B, Alani AW, Rao DA. Polymeric micellar codelivery of resveratrol and curcumin to mitigate in vitro doxorubicin-induced cardiotoxicity. J Pharm Sci. 2014;103(8):2315-22. doi:10.1002/jps.24042.

64. Pramanik D, Campbell NR, Das S, Gupta S, Chenna V, Bisht S, et al. A composite polymer nanoparticle overcomes multidrug resistance and ameliorates doxorubicin-associated cardiomyopathy. Oncotarget. 2012;3(6):640-50.

65. Deveza L, Choi J, Yang F. Therapeutic angiogenesis for treating cardiovascular diseases. Theranostics. 2012;2(8):80114. doi:10.7150/thno.4419.

66. Ding Q, Niu T, Yang Y, Guo Q, Luo F, Qian Z. Preparation of curcumin-loaded poly(ester amine) nanoparticles for the treatment of anti-angiogenesis. J Biomed Nanotechnol. 2014;10(4):632-41.

67. Re F, Cambianica I, Zona C, Sesana S, Gregori M, Rigolio R, et al. Functionalization of liposomes with ApoE-derived peptides at different density affects cellular uptake and drug transport across a blood-brain barrier model. Nanomedicine. 2011;7(5):551-9. doi:10.1016/j.nano.2011.05.004.

68. Doggui S, Sahni JK, Arseneault M, Dao L, Ramassamy C. Neuronal uptake and neuroprotective effect of curcuminloaded PLGA nanoparticles on the human SK-N-SH cell line. J Alzheimer's Dis: JAD. 2012;30(2):377-92. doi:10.3233/JAD2012-112141.

69. Le Droumaguet B, Nicolas J, Brambilla D, Mura S, Maksimenko A, De Kimpe L, et al. Versatile and efficient targeting using a single nanoparticulate platform: application to cancer and Alzheimer's disease. ACS Nano. 2012;6(7):5866-79. doi:10.1021/nn3004372.

70. Mourtas S, Lazar AN, Markoutsa E, Duyckaerts C, Antimisiaris SG. Multifunctional nanoliposomes with curcumin-lipid derivative and brain targeting functionality with potential applications for Alzheimer disease. Eur J Med Chem. 2014;80:175-83. doi:10.1016/j.ejmech.2014.04.050.
71. Taylor M, Moore S, Mourtas S, Niarakis A, Re F, Zona C, et al. Effect of curcumin-associated and lipid ligand-functionalized nanoliposomes on aggregation of the Alzheimer's Abeta peptide. Nanomedicine. 2011;7(5):541-50. doi:10.1016/ j.nano.2011.06.015.

72. Lazar AN, Mourtas S, Youssef I, Parizot C, Dauphin A, Delatour B, et al. Curcumin-conjugated nanoliposomes with high affinity for Abeta deposits: possible applications to Alzheimer disease. Nanomedicine. 2013;9(5):712-21. doi:10.1016/j.nano.2012.11.004.

73. Mourtas S, Canovi M, Zona C, Aurilia D, Niarakis A, La Ferla $\mathrm{B}$, et al. Curcumin-decorated nanoliposomes with very high affinity for amyloid-beta1-42 peptide. Biomaterials. 2011;32(6):1635-45. doi:10.1016/j.biomaterials.2010.10.027.

74. Ray B, Bisht S, Maitra A, Maitra A, Lahiri DK. Neuroprotective and neurorescue effects of a novel polymeric nanoparticle formulation of curcumin (NanoCurc) in the neuronal cell culture and animal model: implications for Alzheimer's disease. J Alzheimer's Dis: JAD. 2011;23(1):6177. doi:10.3233/JAD-2010-101374.

75. Mulik RS, Monkkonen J, Juvonen RO, Mahadik KR, Paradkar AR. ApoE3 mediated poly(butyl) cyanoacrylate nanoparticles containing curcumin: study of enhanced activity of curcumin against beta amyloid induced cytotoxicity using in vitro cell culture model. Mol Pharm. 2010;7(3):815-25. doi:10.1021/ mp900306x.

76. Palmal S, Maity AR, Singh BK, Basu S, Jana NR, Jana NR. Inhibition of amyloid fibril growth and dissolution of amyloid fibrils by curcumin-gold nanoparticles. Chemistry. 2014;20(20):6184-91. doi:10.1002/chem.201400079.

77. Kakkar V, Kaur IP. Evaluating potential of curcumin loaded solid lipid nanoparticles in aluminium induced behavioural, biochemical and histopathological alterations in mice brain. Food Chem Toxicol: Int J Published Br Ind Biol Res Assoc. 2011;49(11):2906-13. doi:10.1016/j.fct.2011.08.006.

78. Doggui S, Belkacemi A, Paka GD, Perrotte M, Pi R, Ramassamy C. Curcumin protects neuronal-like cells against acrolein by restoring Akt and redox signaling pathways. Mol Nutr Food Res. 2013;57(9):1660-70. doi:10.1002/ mnfr.201300130.

79. Cheng KK, Chan PS, Fan S, Kwan SM, Yeung KL, Wang YX, et al. Curcumin-conjugated magnetic nanoparticles for detecting amyloid plaques in Alzheimer's disease mice using magnetic resonance imaging (MRI). Biomaterials. 2015;44:155-72. doi:10.1016/j.biomaterials.2014.12.005.

80. Jaruszewski KM, Curran GL, Swaminathan SK, Rosenberg JT, Grant SC, Ramakrishnan S, et al. Multimodal nanoprobes to target cerebrovascular amyloid in Alzheimer's disease brain. Biomaterials. 2014;35(6):1967-76. doi:10.1016/ j.biomaterials.2013.10.075.

81. Marrache S, Dhar S. Engineering of blended nanoparticle platform for delivery of mitochondria-acting therapeutics. Proc Natl Acad Sci U S A. 2012;109(40):16288-93. doi:10.1073/ pnas.1210096109.

82. Sandhir R, Yadav A, Mehrotra A, Sunkaria A, Singh A, Sharma S. Curcumin nanoparticles attenuate neurochemical and neurobehavioral deficits in experimental model of Huntington's disease. Neruomol Med. 2014;16(1):106-18. doi:10.1007/s12017-013-8261-y.

83. Kakkar V, Mishra AK, Chuttani K, Kaur IP. Proof of concept studies to confirm the delivery of curcumin loaded solid lipid nanoparticles (C-SLNs) to brain. Int J Pharm. 2013;448(2):3549. doi:10.1016/j.ijpharm.2013.03.046.

84. Ramalingam P, Ko YT. A validated LC-MS/MS method for quantitative analysis of curcumin in mouse plasma and brain tissue and its application in pharmacokinetic and brain distribution studies. J Chromatogr B Anal Technol Biomed Life Sci. 2014;969:101-8. doi:10.1016/j.jchromb.2014.08.009.

85. Ramalingam P, Ko YT. Enhanced oral delivery of curcumin from N-trimethyl chitosan surface-modified solid lipid nanoparticles: pharmacokinetic and brain distribution evaluations. Pharm Res. 2015;32(2):389-402. doi:10.1007/s11095-014-1469-1.

86. Ahmad N, Ahmad I, Umar S, Iqbal Z, Samim M, Ahmad FJ. PNIPAM nanoparticles for targeted and enhanced nose-to-brain delivery of curcuminoids: UPLC/ESI-Q-ToF-MS/MS-based 
pharmacokinetics and pharmacodynamic evaluation in cerebral ischemia model. Drug Deliv. 2014:1-20. doi: 10.3109/ 10717544.2014.941076.

87. Ahmad N, Umar S, Ashafaq M, Akhtar M, Iqbal Z, Samim M, et al. A comparative study of PNIPAM nanoparticles of curcumin, demethoxycurcumin, and bisdemethoxycurcumin and their effects on oxidative stress markers in experimental stroke. Protoplasma. 2013;250(6):1327-38. doi:10.1007/s00709013-0516-9.

88. Kalani A, Kamat PK, Kalani K, Tyagi N. Epigenetic impact of curcumin on stroke prevention. Metab Brain Dis. 2015;30(2):427-35. doi:10.1007/s11011-014-9537-0.

89. Kakkar V, Muppu SK, Chopra K, Kaur IP. Curcumin loaded solid lipid nanoparticles: an efficient formulation approach for cerebral ischemic reperfusion injury in rats. Eur $\mathrm{J}$ Pharm Biopharm: Off J Arbeitsgemeinschaft fur Pharm Verfahrenstechnik eV. 2013;85(3 Pt A):339-45. doi:10.1016/ j.ejpb.2013.02.005.

90. Singh AK, Jiang Y, Gupta S, Younus M, Ramzan M. Antiinflammatory potency of nano-formulated puerarin and curcumin in rats subjected to the lipopolysaccharide-induced inflammation. J Med Food. 2013;16(10):899-911. doi:10.1089/ jmf.2012.0049.

91. Beloqui A, Coco R, Memvanga PB, Ucakar B, des Rieux A, Preat V. pH-sensitive nanoparticles for colonic delivery of curcumin in inflammatory bowel disease. Int J Pharm. 2014;473(1-2):203-12. doi:10.1016/j.ijpharm.2014.07.009.

92. Shukla P, Dwivedi P, Gupta PK, Mishra PR. Optimization of novel tocopheryl acetate nanoemulsions for parenteral delivery of curcumin for therapeutic intervention of sepsis. Expert Opin Drug Deliv. 2014;11(11):1697-712. doi:10.1517/ 17425247.2014.932769.

93. Sun D, Zhuang X, Xiang X, Liu Y, Zhang S, Liu C, et al. A novel nanoparticle drug delivery system: the anti-inflammatory activity of curcumin is enhanced when encapsulated in exosomes. Mol Ther: J Am Soc Gene Ther. 2010;18(9):160614. doi:10.1038/mt.2010.105.

94. Chaudhary H, Kohli K, Kumar V. A novel nano-carrier transdermal gel against inflammation. Int $\mathrm{J}$ Pharm. 2014;465(1-2):175-86. doi:10.1016/j.ijpharm.2014.02.023.

95. Wang J, Wang H, Zhu R, Liu Q, Fei J, Wang S. Antiinflammatory activity of curcumin-loaded solid lipid nanoparticles in IL-1beta transgenic mice subjected to the lipopolysaccharide-induced sepsis. Biomaterials. 2015;53:47583. doi:10.1016/j.biomaterials.2015.02.116.

96. Gugulothu D, Kulkarni A, Patravale V, Dandekar P. pHsensitive nanoparticles of curcumin-celecoxib combination: evaluating drug synergy in ulcerative colitis model. J Pharm Sci. 2014;103(2):687-96. doi:10.1002/jps.23828.

97. Singh N, Khullar N, Kakkar V, Kaur IP. Attenuation of carbon tetrachloride-induced hepatic injury with curcumin-loaded solid lipid nanoparticles. BioDrugs: Clin Immunotherapeutics Biopharm Gene Ther. 2014;28(3):297-312. doi:10.1007/s40259014-0086-1.

98. Arora R, Kuhad A, Kaur IP, Chopra K. Curcumin loaded solid lipid nanoparticles ameliorate adjuvant-induced arthritis in rats. Eur J Pain. 2014. doi:10.1002/ejp.620.

99. Maradana MR, Thomas R, O'Sullivan BJ. Targeted delivery of curcumin for treating type 2 diabetes. Mol Nutr Food Res. 2013;57(9):1550-6. doi:10.1002/ mnfr.201200791.

100. Joshi RP, Negi G, Kumar A, Pawar YB, Munjal B, Bansal AK, et al. SNEDDS curcumin formulation leads to enhanced protection from pain and functional deficits associated with diabetic neuropathy: an insight into its mechanism for neuroprotection. Nanomedicine. 2013;9(6):776-85. doi:10.1016/ j.nano.2013.01.001.

101. Devadasu VR, Wadsworth RM, Kumar MN. Protective effects of nanoparticulate coenzyme Q10 and curcumin on inflammatory markers and lipid metabolism in streptozotocin-induced diabetic rats: a possible remedy to diabetic complications. Drug Deliv Transl Res. 2011;1(6):448-55. doi:10.1007/s13346-0110041-3.

102. Yekollu SK, Thomas R, O’Sullivan B. Targeting curcusomes to inflammatory dendritic cells inhibits NF-kappaB and improves insulin resistance in obese mice. Diabetes. 2011;60(11):2928-38. doi:10.2337/db11-0275.

103. Aggarwal BB, Kumar A, Bharti AC. Anticancer potential of curcumin: preclinical and clinical studies. Anticancer Res. 2003;23(1A):363-98.

104. Garbuzenko OB, Winkler J, Tomassone MS, Minko T. Biodegradable Janus nanoparticles for local pulmonary delivery of hydrophilic and hydrophobic molecules to the lungs. Langmuir: ACS J Surf Colloids. 2014;30(43):12941-9. doi:10.1021/la502144z.

105. Wang W, Zhu R, Xie Q, Li A, Xiao Y, Li K, et al. Enhanced bioavailability and efficiency of curcumin for the treatment of asthma by its formulation in solid lipid nanoparticles. Int $\mathrm{J}$ Nanomedicine. 2012;7:3667-77. doi:10.2147/IJN.S30428.

106. Yen FL, Tsai MH, Yang CM, Liang CJ, Lin CC, Chiang YC, et al. Curcumin nanoparticles ameliorate ICAM-1 expression in TNF-alpha-treated lung epithelial cells through p47 (phox) and MAPKs/AP-1 pathways. PLoS One. 2013;8(5), e63845. doi:10.1371/journal.pone.0063845.

107. Kumar A, Glaum M, El-Badri N, Mohapatra S, Haller E, Park $\mathrm{S}$, et al. Initial observations of cell-mediated drug delivery to the deep lung. Cell Transplant. 2011;20(5):609-18. doi:10.3727/ $096368910 X 536491$.

108. Selvam P, El-Sherbiny IM, Smyth HD. Swellable hydrogel particles for controlled release pulmonary administration using propellant-driven metered dose inhalers. J Aerosol Med Pulm Drug Deliv. 2011;24(1):25-34. doi:10.1089/jamp.2010.0830.

109. Ye Y, Li Y, Fang F. Upconversion nanoparticles conjugated with curcumin as a photosensitizer to inhibit methicillin-resistant Staphylococcus aureus in lung under near infrared light. Int $\mathbf{J}$ Nanomedicine. 2014;9:5157-65. doi:10.2147/IJN.S71365.

110. Moghadamtousi SZ, Kadir HA, Hassandarvish P, Tajik H, Abubakar S, Zandi K. A review on antibacterial, antiviral, and antifungal activity of curcumin. BioMed Res Int. 2014;2014:186864. doi:10.1155/2014/186864.

111. Akbik D, Ghadiri M, Chrzanowski W, Rohanizadeh R. Curcumin as a wound healing agent. Life Sci. 2014;116(1):1-7. doi:10.1016/j.lfs.2014.08.016.

112. Bhawana, Basniwal RK, Buttar HS, Jain VK, Jain N. Curcumin nanoparticles: preparation, characterization, and antimicrobial study. J Agric Food Chem. 2011;59(5):2056-61. doi:10.1021/ jf104402t.

113. Dogra N, Choudhary R, Kohli P, Haddock JD, Makwana S, Horev B, et al. Polydiacetylene nanovesicles as carriers of natural phenylpropanoids for creating antimicrobial foodcontact surfaces. J Agric Food Chem. 2015;63(9):2557-65. doi:10.1021/j5505442w.

114. Gong C, Wu Q, Wang Y, Zhang D, Luo F, Zhao X, et al. A biodegradable hydrogel system containing curcumin encapsulated in micelles for cutaneous wound healing. Biomaterials. 2013;34(27):6377-87. doi:10.1016/j.biomaterials.2013.05.005.

115. Krausz AE, Adler BL, Cabral V, Navati M, Doerner J, Charafeddine RA, et al. Curcumin-encapsulated nanoparticles as innovative antimicrobial and wound healing agent. Nanomedicine. 2015;11(1):195-206. doi:10.1016/ j.nano.2014.09.004.

116. Said DE, Elsamad LM, Gohar YM. Validity of silver, chitosan, and curcumin nanoparticles as anti-Giardia agents. Parasitol Res. 2012;111(2):545-54. doi:10.1007/s00436-012-2866-1.

117. Pescosolido N, Giannotti R, Plateroti AM, Pascarella A, Nebbioso M. Curcumin: therapeutical potential in ophthalmology. Planta Med. 2014;80(4):249-54. doi:10.1055/s-00331351074.

118. Lou J, Hu W, Tian R, Zhang H, Jia Y, Zhang J, et al. Optimization and evaluation of a thermoresponsive ophthalmic gel containing curcumin-loaded albumin nanoparticles. Int J Nanomedicine. 2014;9:2517-25. doi:10.2147/IJN.S60270.

119. Pradhan N, Guha R, Chowdhury S, Nandi S, Konar A, Hazra S. Curcumin nanoparticles inhibit corneal neovascularization. J Mol Med. 2015. doi:10.1007/s00109-015-1277-z.

120. Rachmawati H, Edityaningrum CA, Mauludin R. Molecular inclusion complex of curcumin-beta-cyclodextrin nanoparticle to enhance curcumin skin permeability from hydrophilic matrix gel. AAPS PharmSciTech. 2013;14(4):1303-12. doi:10.1208/ s12249-013-0023-5. 
121. Janesirisakule S, Sinthusake T, Wanichwecharungruang S. Nanocarrier with self-antioxidative property for stabilizing and delivering ascorbyl palmitate into skin. J Pharm Sci. 2013;102(8):2770-9. doi:10.1002/jps.23641.

122. Suwannateep N, Wanichwecharungruang S, Fluhr J, Patzelt A, Lademann J, Meinke MC. Comparison of two encapsulated curcumin particular systems contained in different formulations with regard to in vitro skin penetration. Skin Res Technol: Off J Int Soc Bioeng Skin. 2013;19(1):1-9. doi:10.1111/j.16000846.2011.00600.x.

123. Castangia I, Nácher A, Caddeo C, Valenti D, Fadda AM, DíezSales $\mathrm{O}$, et al. Fabrication of quercetin and curcumin bionanovesicles for the prevention and rapid regeneration of full-thickness skin defects on mice. Acta Biomater. 2014;10(3):1292-300. doi:10.1016/j.actbio.2013.11.005.

124. Suwannateep N, Wanichwecharungruang S, Haag SF, Devahastin S, Groth N, Fluhr JW, et al. Encapsulated curcumin results in prolonged curcumin activity in vitro and radical scavenging activity ex vivo on skin after UVB-irradiation. Eur J Pharm Biopharmaceutics: Off J Arbeitsgemeinschaft fur Pharmazeutische Verfahrenstechnik eV. 2012;82(3):485-90. doi:10.1016/j.ejpb.2012.08.010.

125. Nayak AP, Tiyaboonchai W, Patankar S, Madhusudhan B, Souto EB. Curcuminoids-loaded lipid nanoparticles: novel approach towards malaria treatment. Colloids Surf B: Biointerfaces. 2010;81(1):263-73. doi:10.1016/ j.colsurfb.2010.07.020.

126. Isacchi B, Bergonzi MC, Grazioso M, Righeschi C, Pietretti A, Severini C, et al. Artemisinin and artemisinin plus curcumin liposomal formulations: enhanced antimalarial efficacy against Plasmodium berghei-infected mice. Eur J Pharm Biopharm: Off J Arbeitsgemeinschaft fur Pharmazeutische Verfahrenstechnik eV. 2012;80(3):528-34. doi:10.1016/j.ejpb.2011.11.015.

127. Akhtar F, Rizvi MM, Kar SK. Oral delivery of curcumin bound to chitosan nanoparticles cured Plasmodium yoelii infected mice. Biotechnol Adv. 2012;30(1):310-20. doi:10.1016/ j.biotechadv.2011.05.009.
128. Egan ME, Pearson M, Weiner SA, Rajendran V, Rubin D, Glockner-Pagel J, et al. Curcumin, a major constituent of turmeric, corrects cystic fibrosis defects. Science. 2004;304(5670):600-2. doi:10.1126/science.1093941.

129. Lipecka J, Norez C, Bensalem N, Baudouin-Legros M, Planelles G, Becq F, et al. Rescue of DeltaF508-CFTR (cystic fibrosis transmembrane conductance regulator) by curcumin: involvement of the keratin 18 network. J Pharmacol Exp Ther. 2006;317(2):500-5. doi:10.1124/jpet.105.097667.

130. Cartiera MS, Ferreira EC, Caputo C, Egan ME, Caplan MJ, Saltzman WM. Partial correction of cystic fibrosis defects with PLGA nanoparticles encapsulating curcumin. Mol Pharm. 2010;7(1):86-93. doi:10.1021/mp900138a.

131. Heo DN, Ko WK, Moon HJ, Kim HJ, Lee SJ, Lee JB, et al. Inhibition of osteoclast differentiation by gold nanoparticles functionalized with cyclodextrin curcumin complexes. ACS Nano. 2014;8(12):12049-62. doi:10.1021/ nn504329u.

132. Potter KA, Jorfi M, Householder KT, Foster EJ, Weder C, Capadona JR. Curcumin-releasing mechanically adaptive intracortical implants improve the proximal neuronal density and blood-brain barrier stability. Acta Biomater. 2014;10(5):2209-22. doi:10.1016/j.actbio.2014.01.018.

133. Sankar P, Telang AG, Kalaivanan R, Karunakaran V, Suresh S, Kesavan M. Oral nanoparticulate curcumin combating arsenicinduced oxidative damage in kidney and brain of rats. Toxicol Ind Health. 2013. doi:10.1177/0748233713498455.

134. Ahmad N, Warsi MH, Iqbal Z, Samim M, Ahmad FJ. Quantification of curcumin, demethoxycurcumin, and bisdemethoxycurcumin in rodent brain by UHPLC/ESI-Q-TOF-MS/MS after intra-nasal administration of curcuminoids loaded PNIPAM nanoparticles. Drug Test Anal. 2014;6(3):257-67. doi:10.1002/dta.1472.

135. Gandapu U, Chaitanya RK, Kishore G, Reddy RC, Kondapi AK. Curcumin-loaded apotransferrin nanoparticles provide efficient cellular uptake and effectively inhibit HIV-1 replication in vitro. PLoS One. 2011;6(8), e23388. doi:10.1371/ journal.pone.0023388. 